\title{
Vaporizing Foil Actuator Welding as a Competing Technology to Magnetic Pulse Welding
}

\author{
Marlon Hahn ${ }^{1, a}$, Christian Weddeling ${ }^{\mathrm{a}}$, Geoffrey Taber ${ }^{\mathrm{b}}$, Anupam Vivek ${ }^{\mathrm{b}}$, Glenn S. \\ Daehn $^{\text {b }}$ A. Erman Tekkaya ${ }^{\mathrm{a}}$ \\ ${ }^{a}$ Institute of Forming Technology and Lightweight Construction, TU Dortmund University, Baroper Str. 303, \\ 44227 Dortmund, Germany \\ ${ }^{\mathrm{b}}$ Department of Materials Science and Engineering, The Ohio State University, 477 Watts Hall, 2041 College \\ Rd., Columbus, OH 43210, USA
}

Keywords:

Collision welding, Vaporizing Foil Actuator Welding (VFAW), Magnetic Pulse Welding (MPW), Analytical model

\begin{abstract}
Photonic Doppler velocimetry was applied to compare magnetic pulse welding and vaporizing foil actuator welding against each other in the form of lap joints made of 5000 series aluminum alloy sheets under identical experimental conditions which are: charging energies of the pulse generator, specimen geometry, initial distances between flyer and target plate. Impact velocities resulting from rapidly vaporizing aluminum foils were up to three times higher than those of purely electromagnetically accelerated flyer plates. No magnetic pulse welds were achieved, while every vaporizing foil experiment yielded a strong weld in that failure always occurred in the joining partners instead of in the weld seam during tensile tests. An analytical model to calculate the transient flyer velocity is presented and compared to the measurements. The average deviation between model and experiment is about $11 \%$ with regard to the impact velocity. Hence, the model may be used for the process design of collision welds generated by vaporizing foil actuators.
\end{abstract}

\section{Introduction}

Multi-material designs for complex lightweight applications become more and more important in the context of reducing fossil fuel consumption and subsequent exhaust emissions. Within the scope of such designs various materials are deployed with respect to the mechanical loads they are subjected to. Conventional joining techniques are not always capable of meeting the challenging requirements of those multi-material designs because of different thermal properties (e.g. melting point) of the joining partners, for example. Screw and rivet connections are usually relatively heavy and expensive, while adhesive bonding implies prolonged production times due to the curing process. As a consequence, a rising demand for alternative joining methods can be noticed. In the case of firmly bonded metals, solid-state joining of similar as well as conventionally almost unweldable dissimilar

\footnotetext{
${ }^{1}$ Corresponding author. Tel.: +49 231755 8415. E-mail: marlon.hahn@iul.tu-dortmund.de
} 
metals (e.g. steel and aluminum alloys) through high velocity forming, also referred to as collision welding, is believed to have great potential. As emphasized by Zhang (2010), another advantage of collision welding is the elimination or at least minimization of problems associated with a heataffected zone (HAZ), such as the formation of brittle intermetallic phases or cracking in fusion welding. Consequently, the strength of collision welds can reach or even exceed the one of the weakest parent material.

\section{Collision welding methods}

Known collision welding methods are (Zhang, 2010): explosive welding (EXW; possible workpiece dimensions are in the order of meters), laser impact welding (LIW; dimensions of the order of millimeters), and magnetic pulse welding (MPW; dimensions of the order of centimeters). A more recent method introduced by Vivek et al. (2013) is called vaporizing foil actuator welding (VFAW; same dimensions as in MPW). The two latter methods constitute the core of the present work and are treated in more detail in the ensuing paragraphs. All mentioned joining technologies basically underlie the same physical mechanisms, which are depicted in Fig. 1.

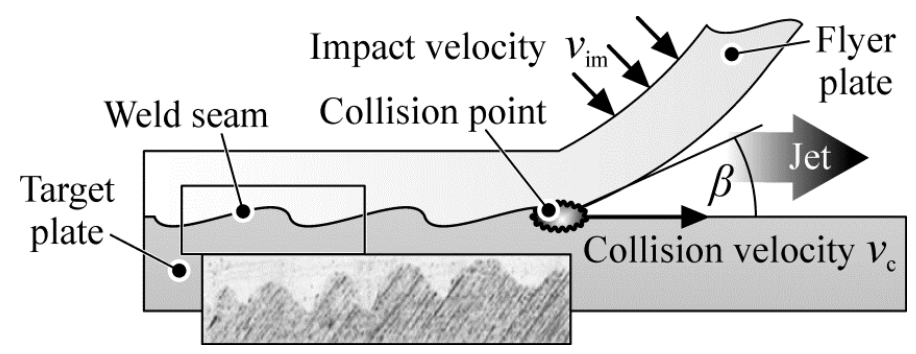

Figure 1: Principle of collision welding (Mori et al., 2013).

At least one of the joining partners - the flyer - is accelerated rapidly to an appropriate velocity $v_{\text {im }}$ at which it collides with the target plate under a certain impact angle, $\beta$, resulting in impact pressures of the order of several gigapascals (Mori et al., 2013). As summarized by Shribman (2008), this comes along with the formation of a jet that removes all oxides and surface contaminants in the weld area so that an atomic bonding can be achieved between the two mating metal surfaces. The weld seam then propagates with collision velocity $v_{\mathrm{c}}$, which is geometrically related to $v_{\mathrm{im}}$ through $\beta$ (Mousavi and Sartangi, 2009). In the course of this, a wavy interface morphology as depicted in Fig. 1 may evolve. Regarding the actual mechanism causing such a wavy pattern, a few theories exist being still under discussion in the literature. A common explanation has been given by BenArtzy et al. (2010). After reviewing earlier theories, the authors experimentally established that interface waves were formed in a Kelvin-Helmholtz instability in the case of tubular MPW joints. Reflected shock waves were found to be the reason for the liquid-like behavior of the metals across their interface. Vivek et al. (2013) mention that successful welds generally occur at angles between 
$5^{\circ}$ and $20^{\circ}$ as well as at impact velocities ranging from $150 \mathrm{~m} / \mathrm{s}$ to $1500 \mathrm{~m} / \mathrm{s}$. A weldability domain of the crucial parameters $v_{\mathrm{c}}$ and $\beta$ required for a specific combination of materials may be represented by a so-called welding window. It also reveals whether or not waves and interlayers are observable in the weld seam. Kore et al. (2009) concluded from scanning electron microscopy (SEM) and X-ray diffraction (XRD) analysis of Mg AZ31 to Al AA3003 magnetic pulse welds with wavy interface morphology that the base materials do not undergo a melting and solidification stage. In contrast, Göbel et al. (2010) used similar techniques to prove that both intermetallic phases in "meld pockets" and virtually waveless intermetallic transition layers emerge during magnetic pulse welding of $\mathrm{Al}$ tubes and $\mathrm{Cu}$ cylinders. Welding windows originate from EXW and are derived in detail in Mousavi and Sartangi (2009) for the explosive welding of cp Ti and AISI 304 stainless steel. Verstraete et al. (2011) yet point out that impact angle and velocity are not constant during MPW, which makes the generation of such welding windows rather difficult compared to EXW. The same applies to VFAW. Vivek et al. (2014c), however, lately applied the concept of welding windows successfully to cp Ti-Cu 110 VFAW joints. Their work combined grooved target plates with predetermined angles, photonic Doppler velocimetry to record the transient flyer velocities, and SEM analyses.

\subsection{Fundamentals of electromagnetic forming (EMF)}

Since MPW makes use of the electromagnetic forming technology in order to join the flyer and target plate, the functional principle of EMF is briefly presented in the following. The forming tool consists of an electrically insulated coil, more generally referred to as actuator, which is connected to a capacitor bank pulse power supply (EMF machine) and at the same time placed close to the workpiece or flyer (compare Fig.2). This entire system may be approximated by a simple series $R L C$ (resistance-inductance-capacitance) circuit with constant elements (Winkler, 1973). The capacitor is then discharged usually within a few tens of microseconds to accelerate the flyer electromagnetically.

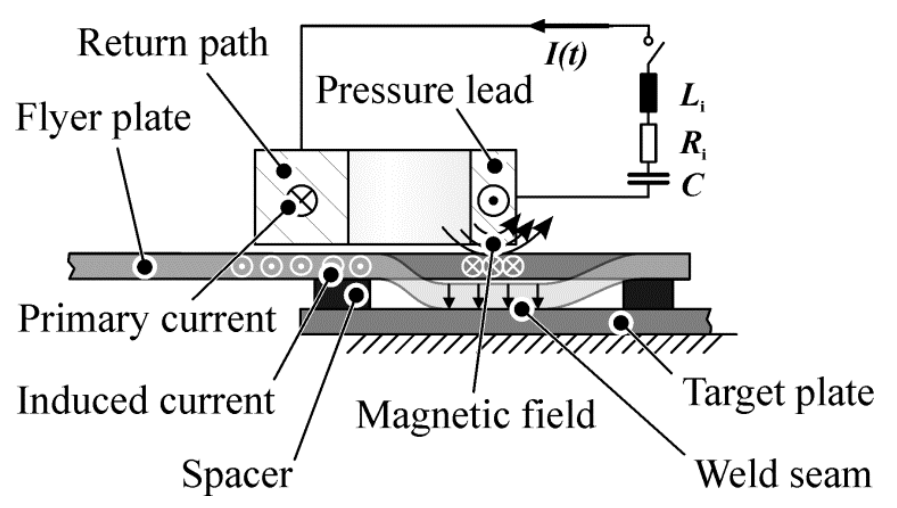

Figure 2: Schematic of MPW for lap joints as pictured in Weddeling et al. (2014). 
Beerwald (2005) enumerates that typical charging energies differ from 1 to $100 \mathrm{~kJ}$, charging voltages are in the range of 3 to $25 \mathrm{kV}$. This results in peak currents of up to a few $100 \mathrm{kA}$. When the driving current pulse passes through the pressure lead of the coil, opposing eddy currents are induced in the workpiece under the terms of the electromagnetic laws of Lenz and Faraday. Two nearby currents flowing in the opposite direction (primary current in the coil and secondary current in the workpiece) repel each other due to the Lorentz force which acts as the forming force. High conductivity flyers may be accelerated directly in EMF, otherwise, thin high-conductivity materials can be used as a driver plate, as for example investigated by Li et al. (2013) for the electromagnetic launch of $1 \mathrm{~mm}$ thick Ti-6Al-4V plates. Since the Lorentz forces take effect on both the workpiece and the coil, one of the biggest problems in EMF with regard to mass production still is the relatively short lifetime of a coil (Psyk et al., 2011). EMF coil designs can generally be classified into three categories introduced by Harvey and Brower (1958): compression coils (usually solenoids), expansion coils (also usually solenoids) as well as coils for sheet metal forming. For the latter coil type, several conductor geometries have been developed. A recent one established by Kamal (2005) is named uniform pressure electromagnetic actuator (UPEA) and was modified for magnetic pulse welding by Weddeling et al. (2014). As studied in Zhang et al. (2010), MPW coils for direct lap joints can be designed as a simple one-turn coil consisting of a pressure lead and a wider return path outside the forming area (see Fig. 2). Aizawa (2003) showed that the return path can also act as a second pressure lead if it is small enough and positioned below the target plate so that both joining partners are accelerated against each other. The coil geometry greatly influences the circuit parameters, especially the coil inductance. As explained in Daehn (2010), low capacitances and low inductances favor high frequencies which are essential for inducing intense eddy current densities and thus sufficiently high Lorentz forces in the workpiece. An upper bound for the maximum possible frequency is given by the short circuit frequency of the EMF machine. Typical values range from 20 to $100 \mathrm{kHz}$ (Henselek et al., 2004).

\subsection{Fundamentals of vaporizing foil actuators (VFA)}

The effects of electrically driven rapidly vaporizing foils (or wires), also referred to as electrical explosion of conductors, have been the subject of several studies over the past decades (Chace and Levin, 1960). Exemplary works include the production of nano-sized powders (Zou et al., 2012a) or the shaping of high current pulses (Bealing and Carpenter, 1972). Other common applications deal with shock wave studies (Weingart et al., 1976). However, vaporizing foil actuators have not been used for welding until the recent work of Vivek et al. (2013). In the following, the basic physical mechanisms of vaporizing conductors are outlined. VFAW basically 
utilizes the same machinery as EMF, but in this case the discharge current of the capacitor rapidly vaporizes a thin foil in order to launch the metal flyer plate, as indicated in Fig. 3.

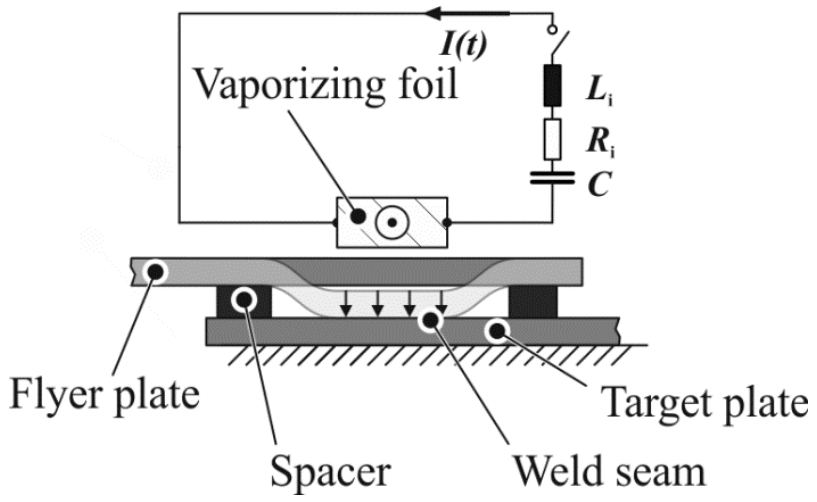

Figure 3: Schematic of VFAW for lap joints.

When a large pulsed current passes through a thin metallic conductor (e.g. foil), rapid non-linear changes in physical states take place. As described in Wang et al. (2011), these changes can be divided into basically five stages: the heating stage, the melting stage, the heating stage of liquid metal before the vaporizing stage, and the plasma forming stage. Once the actuator is in the gaseous state its resistance is a couple of orders higher than in the initial stage. Chace and Levin (1960) claim that the heating time of a fast electrical vaporization is long enough for current propagation over the cross-section of the conductor, but shorter than the time required for the evolution of magnetohydrodynamic and capillary instabilities. Chau et al. (1980) state that the heating time is also shorter than the thermal diffusion time away from the conductor. Consequently, energy exceeding the theoretical heat of vaporization can be deposited in the actuator before it vaporizes. The instant of vaporization or burst time $t_{\mathrm{B}}$ - and therefore the beginning of violent expansion - is indicated by the peak in voltage and is initiated by the heat-induced destruction of the dynamic equilibrium between the expansive vapor pressure and the counteracting Lorentz force around the conductor. Due to this equilibrium and the restraining surrounding insulation, the actuator can maintain its shape and keep overheating until the vaporization starts (Zou et al., 2012b). From $t_{\mathrm{B}}$ on, the intense pressure of the expanding vapor or plasma acts as forming pressure for the flyer plate. As investigated in Vivek et al. (2014a), an elastomer plate (e.g. polyurethane) can be put between the foil and the workpiece to serve as an elastic transfer medium for the pressure pulse, which is then spread over an area larger than the actual geometry of the foil. A main factor of influence on achievable pressures, and therefore flyer velocities, is constituted by the amount of electrical energy $E_{\mathrm{D}}$ that can be deposited into the foil until it bursts. Referring to Vivek et al. (2014a), it can be computed as

$$
E_{\mathrm{D}}=\int_{0}^{t_{\mathrm{B}}} U I \mathrm{~d} t
$$


where $U$ represents the voltage drop across the length and $I$ the current through the foil. Grigoriev and Pavlenko (2009) experimentally found a linearly increasing correlation between the energy supplied to various foil materials and the resultant pressure. The authors were able to inject up to twice the energy required for boiling the foil material, yielding pressure amplitudes in the range of $2.5 \mathrm{GPa}$. Sarkisov et al. (2004) proved that the amount of energy deposited into a metal wire depends on the rate of energy deposition or heating rate and, therefore, on the current rate. Increasing the current rate from 20 to $150 \mathrm{~A} / \mathrm{ns}$ allowed the deposition of almost three times more energy. As resumed in Sedoi et al. (1999), this conflicts with some earlier studies where authors state that the storable energy per unit mass is a constant for a given metal. Chemical reactions can also play a noteworthy role in vaporizing foil technology. Nelson et al. (1999) found that the exothermic reaction between aluminum vapor and water leads to significantly higher peak pressures as compared to similar underwater vaporizations of tungsten wires at the same input energy. By contrast, Lee and Ford (1988) revealed that the chemical reaction, which is $2 \mathrm{Al}+3 \mathrm{H}_{2} \mathrm{O}=\mathrm{Al}_{2} \mathrm{O}_{3}+3 \mathrm{H}_{2}$, only contributes sparsely on the shock front pressure because it occurs approximately $200 \mu \mathrm{s}$ after the vaporization of the aluminum wire. The reaction kinetics of Al with air were studied by Sarathi et al. (2004). They found that there is a time lag between the vaporization and the beginning of intense oxidation that is at least twice as long as the vaporization period. In case of VFAW, it can therefore be assumed that the travel of the flyer does not last long enough to allow chemical reactions to develop before colliding with the target plate. Since the flyer velocity is a crucial parameter in VFAW, there is a need to determine it. A common approach to estimate a final flyer plate velocity $v_{\max }$ is to apply the so-called electrical Gurney model introduced by Tucker and Stanton (1975), which originates from studies about explosives. If the vaporizing foil is assumed to be backed by infinite mass, it can be written as follows:

$$
v_{\max }=\sqrt{\frac{2 E_{\mathrm{eg}}}{(m / c+1 / 3)}}=\sqrt{\frac{2 \eta P_{\mathrm{b}} \tau}{(m / c+1 / 3)}} .
$$

Here, $m$ and $c$ represent the accelerated flyer mass and the mass of the vaporizing foil, respectively. The product $\eta P_{\mathrm{b}} \tau$ is defined as electrical Gurney energy $E_{\mathrm{eg}}, P_{\mathrm{b}}$ is the peak burst power per unit mass, $\eta$ is the Gurney efficiency, and $\tau$ is a factor having units of time. Tucker and Stanton (1975) concluded that $\eta$ can be estimated at 0.5 . They also developed and verified the equation

$E_{\mathrm{eg}}=K J_{\mathrm{b}}^{n}$

where the only variable $J_{\mathrm{b}}$ is burst current density; $K$ and $n$ are empirical constants for a given experimental setup. Another model for predicting flyer velocities for VFA, which comprises energy balance considerations formulated by Osher et al. (1989), is derived in Vivek et al. (2014b). To 
verify it, the authors experimentally varied the thickness of aluminum foil as well as the input energy and recorded velocities ranging from $400 \mathrm{~m} / \mathrm{s}$ to $1000 \mathrm{~m} / \mathrm{s}$ for $0.508 \mathrm{~mm}$ thick flyers made of 2024 aluminum alloy. Yet, the models mentioned above do not allow adequate transient calculations of velocity because they only incorporate the final kinetic energy of the flyer. Knowing the velocity history of the flyer, however, is important for the process design in collision welding since the impact with the target happens at a predetermined distance (standoff). A model to compute velocitytime curves for vaporizing foils is introduced in Schmidt et al. (1977), but the governing differential equations require a numerical solver to specify values for the velocity. A more complex simulation model which takes heat conduction, magnetic pressure, and electrical power into account on the basis of magnetohydrodynamic (MHD) equations is presented and experimentally verified in Wang et al. (2011).

VFAW seems to be a promising alternative to MPW due to the following reasons: Higher flyer velocities can be expected, there are no tool life problems since foils are disposable low-cost actuators, workpieces do not need to be good electrical conductors. For collision welded lap joints both methods have not yet been directly compared with each other under identical conditions of charging energy, capacitor bank configuration, specimen material, and specimen geometry. Therefore, such a comparison is carried out experimentally within the scope of this work. Since no closed-form solutions for calculating velocity-time histories for VFA can be found in literature so far, a simple model is also suggested and verified here to provide the possibility of estimating flyer plate impact velocities without the need for extensive velocity measurements. It is an analytical model and mainly based on continuity and mechanical equilibrium considerations as well as on a modified version of the electrical Gurney model. The required input data for this model only consist of current-time and voltage-time curves, geometric data, and some basic material parameters.

\section{Analytical model for VFA}

\subsection{Velocity field of the flyer}

The flyer plate deforms plastically during the violent vapor expansion. Thus, a velocity field that does not violate the yield condition must be found for the flyer. Due to the fact that the flyer is only fixed on two sites (via the spacers), a one-dimensional stress state may me assumed so that a crosssection of the flyer can be treated as a beam. A further simplification is to assume rigid-perfectly plastic beams where the yield condition can be expressed through the bending moment. The forming pressure generated during vaporization acts in the region where the foil is placed. The flyer can then be considered as a fully clamped beam under partial uniform loading $p$ in the middle section. If $p$, which is of the order of gigapascals in VFAW, is several times larger than the static pressure 
necessary for a plastic collapse of the beam, a kinematically and statically admissible velocity field for such a system may be taken from Martins and Symonds (1965). It is depicted in Fig. 4.

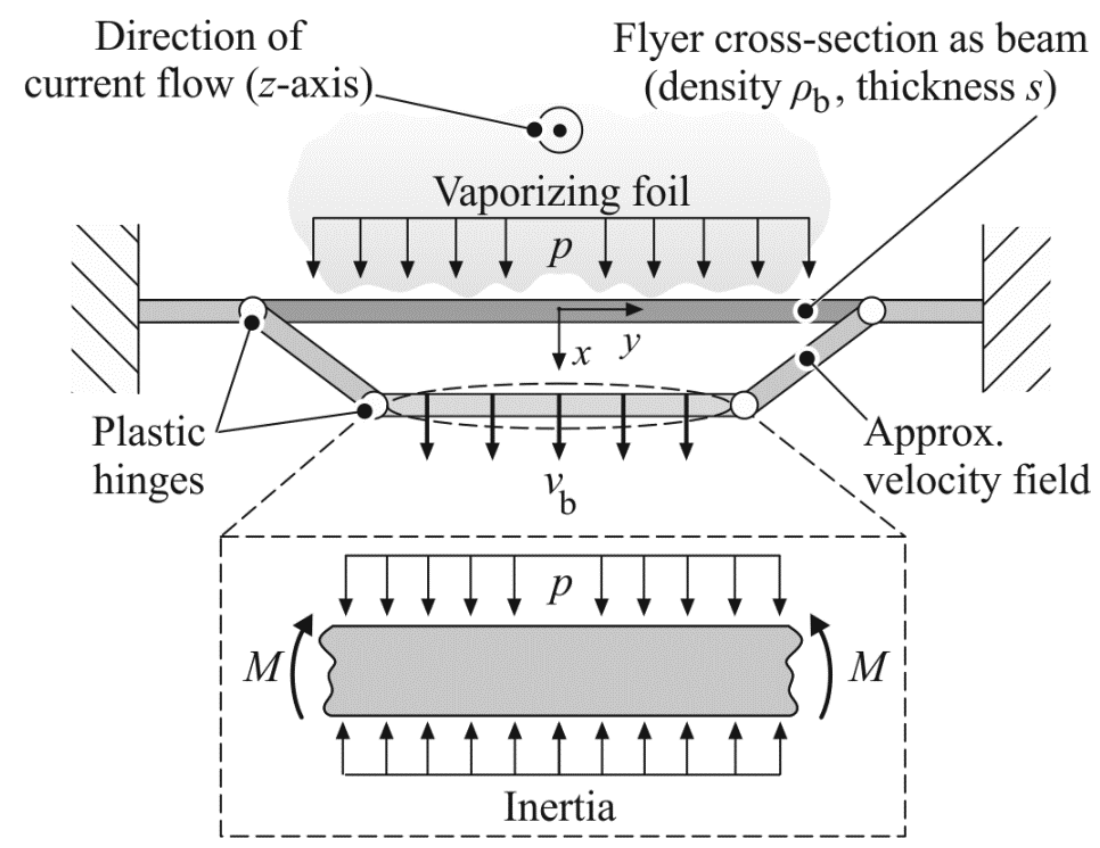

Figure 4: Velocity field of the flyer during vaporization.

There, the magnitude of the bending moment inside all horizontal parts of the beam equals the fully plastic moment for the cross-section. Plasticized parts are connected to rigid beam parts by so-called plastic hinges. These hinges remain stationary in case of temporally rectangular pressure pulses (Jones, 1989). However, it is assumed that a middle fraction of the flyer also remains approximately horizontal in the course of a time-varying pressure pulse until hitting the nearby target. Referring to Jones (1989) and Fig. 4, the dynamic behavior of the beam is governed by the equation

$$
\frac{\partial^{2} M}{\partial y^{2}}=-p+s \rho_{\mathrm{b}} \frac{\partial v_{\mathrm{b}}}{\partial t}
$$

where $M$ is the moment per unit length about the $z$-axis. The density of the flyer $\rho_{\mathrm{b}}$ as well as its thickness $s$ are assumed to stay constant. Since the moment does not vary with $y$ inside the horizontal beam parts $\left(\partial M / \partial y=0=\partial^{2} M / \partial y^{2}\right)$, the velocity $v_{\mathrm{b}}$ only depends on time $t$, so that Eq. (4) can be rewritten as

$$
p=s \rho_{\mathrm{b}} \frac{\mathrm{d} v_{\mathrm{b}}}{\mathrm{d} t}
$$

for the regarded middle part of the flyer. Eq (5) is nothing but Newton's second law. It is noted that this simplified approach is not suitable for free forming experiments without a target where larger distances need to be covered. 


\subsection{Minimum gas particle velocity}

The model proposed here does not incorporate an electromagnetic flyer acceleration arising from the Lorentz force. Consequently, the flyer plate is assumed to be at rest before the foil bursts, although this might not be the case for electrically conductive flyer materials. Until shortly before the burst the foil is interpreted as an enclosed gas volume with constant initial density $\rho_{0}$, as illustrated in Fig. 5 .

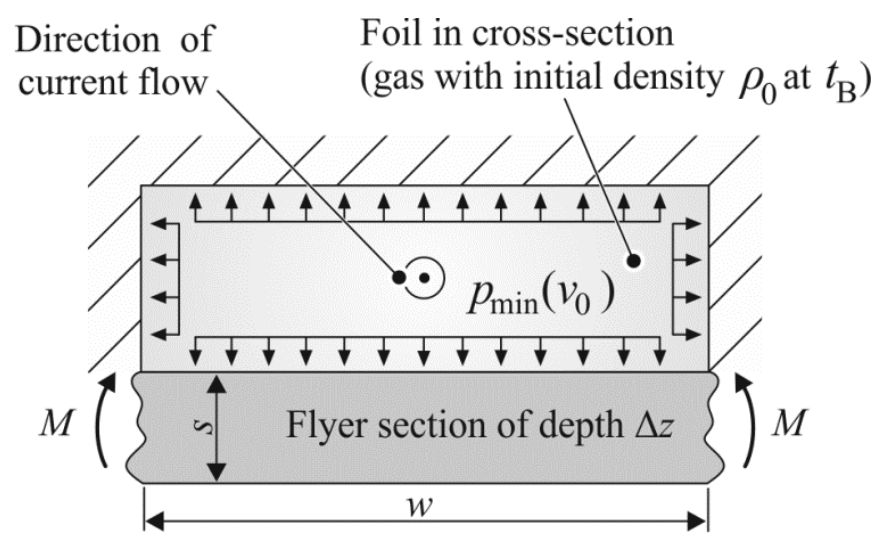

Figure 5: Foil and flyer section before the burst.

According to the kinetic theory of gases (Loeb, 1927), the mean gas particle velocity $v_{0}$ leads to a homogenous pressure $p_{\min }$ for which the following applies:

$p_{\min }=\frac{\rho_{0}}{3} v_{0}^{2}$

Keeping in mind that electromagnetic effects are neglected, the flyer will only be accelerated sufficiently at the burst time if the particle velocity is high enough to cause a plastification of the flyer. To ensure that $v_{0}$ is not chosen too low, the flyer segment over the foil width $w$ is seen as a fully clamped beam here. The resulting elastic bending moment $M_{\mathrm{el}}$ in the flyer can then be derived from Young and Budynas (2002) as

$M_{e l}=\frac{\rho_{0} v_{0}^{2} w^{2} \Delta z}{36}$

where pressure has already been eliminated by inserting Eq. (6). In order to make the flyer move plastically, the elastic moment has to reach the fully plastic moment $M_{\mathrm{pl}}$, which is expressed as

$M_{p l}=\frac{1}{4} \sigma_{\mathrm{Y}} s^{2} \Delta z$

This equation, where $\sigma_{Y}$ denotes the flow stress of a perfectly plastic flyer material, can be found in elementary bending theory (Reissner et al., 1990). After equating $M_{\mathrm{el}}$ and $M_{\mathrm{pl}}$, rearranging yields 
$v_{0}=\sqrt{\frac{\sigma_{\mathrm{Y}}}{\rho_{0}}} \frac{3 s}{w}$.

This required minimum gas particle velocity will be used as a boundary condition.

\subsection{Maximum flyer velocity}

For estimating the maximum velocity $v_{\max }$ of the flyer plate the electrical Gurney model is used (compare Eq. (2)), but in the simplified form of

$v_{\max }=\sqrt{\frac{E_{\mathrm{D}}}{c}}\left(\frac{m}{c}+\frac{1}{3}\right)^{-1 / 2}$.

Here, $E_{\mathrm{D}}$ is the energy deposition according to Eq. (1). The flyer mass that initially covers the narrowest foil section and that is situated between the spacers is chosen as $m$, since almost this entire segment is being pushed onto the target during the welding process. The energy deposition is presumed to be concentrated in the narrowest foil section (active foil region). This implies that $c$ can be approximated by the mass of this active foil region. For the values used in this work a relatively high $\mathrm{m} / \mathrm{c}$ ratio of about 32 is obtained. Certainly, the point when $v_{\max }$ actually occurs needs to be estimated, since Eq. (10) is just based on a final energy balance and does not provide information about the time course. Once the vapor expansion starts, energy will still be injected into the vaporizing foil and contribute to the flyer acceleration. Therefore, a conversion from resistive power of the foil to mechanical power of the flyer is considered (beginning from the burst time $t_{\mathrm{B}}$ ):

$$
\zeta U I=\zeta R I^{2}=m \frac{\mathrm{d} v_{\mathrm{b}}}{\mathrm{d} t} v_{\mathrm{b}}
$$

$\zeta>0$ denotes an unknown conversion efficiency function, $R$ the non-linear resistance of the foil. Experimentally obtained (smoothed) voltage-time, current-time, as well as velocity-time traces are given as illustration in Fig. 6. 


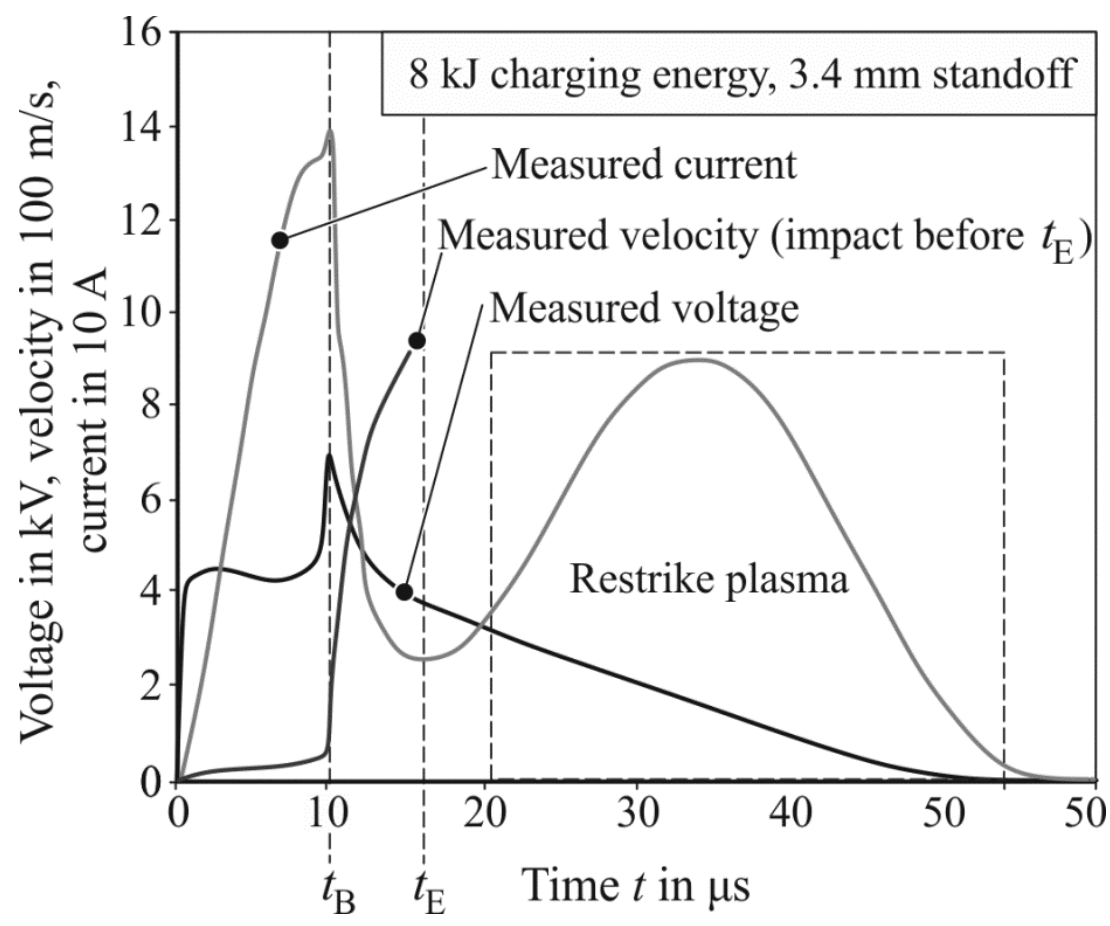

Figure 6: Experimental voltage, velocity, and current traces for VFAW.

It is reasonable to expect a monotonically increasing flyer velocity (acceleration $\mathrm{d} v_{\mathrm{b}} / \mathrm{d} t \geq 0$ ) until the global maximum $v_{\max }$ is reached. Thus, with regard to Eq. (11) and Fig. 6, $v_{\max }$ may occur when the current becomes (approximately) zero, at $t=t_{\mathrm{E}}$. Afterwards, in the course of the restrike, the vapor is assumed to be already expanded to a state where it can no longer accelerate the flyer. Hence, the second boundary condition is determined as

$v_{\mathrm{b}}\left(t_{\mathrm{E}}\right)=v_{\max }$

Yet it is noted that another approach for estimating $t_{\mathrm{E}}$ must be developed if the current does not exhibit a distinct minimum as in Fig. 6. The current flow during the formation of the restrike plasma allows the capacitor to be discharged completely. More detailed information about restrike phenomena can, for instance, be found in Sinton (2011).

\subsection{Temporal evolution of flyer velocity}

The kinetic gas theory, as incorporated in Eq. (6), only applies for a static flyer until right before the foil bursts. Once the vapor or plasma expansion has started $\left(t \geq t_{\mathrm{B}}\right)$, particle velocity $v$, pressure $p$, and density $\rho$ vary temporally as well as spatially. This can be taken into consideration by utilizing the continuity equation for compressible one-dimensional gas flow. A combination with the adiabatic equation of state allows eliminating the density so that

$$
\frac{\partial p}{\partial t}+v \frac{\partial p}{\partial x}=-\gamma p \frac{\partial v}{\partial x}
$$


is obtained. This equation may be found in Pécseli (2012). For chemical elements in the gaseous state (here: Al) or monatomic gases $\gamma=5 / 3$ applies (Loeb, 1927). The left-hand side of Eq. (13) is consistent with the substantial derivative of pressure, $\mathrm{d} p / \mathrm{d} t$. The total differential of $v$ can be expressed as

$$
\mathrm{d} v=\mathrm{d}_{t} v+\mathrm{d}_{x} v \quad \text { with } \quad \frac{\mathrm{d}_{x} v}{\mathrm{~d} x} \equiv \frac{\partial v}{\partial x}
$$

It is reasonable to suppose $\mathrm{d}_{x} v / \mathrm{d} x>0$ and $\mathrm{d}_{t} v / \mathrm{d} t>0$ for the acceleration stage. To make it mathematically manageable, a simplification stating that the velocity increases with time $t$ in the same way as it does spatially with $x$ is made, but only for the particles situated on the flyer surface, at $x=x_{\mathrm{b}}$. There, the total differential may then be written as

$$
\mathrm{d} v=\mathrm{d}_{t} v+\mathrm{d}_{x} v 2 \mathrm{~d}_{x} v
$$

Taking this into account and keeping $v=\mathrm{d} x / \mathrm{d} t$ in mind, Eq. (13), after some manipulations, can be rewritten as

$$
\frac{\gamma}{v} \mathrm{~d} v=-\frac{2}{p} \mathrm{~d} p
$$

The integration of this equation eventually leads to the following explicit pressure-velocity relation:

$$
p=p_{0}\left(\frac{v_{0}}{v}\right)^{\gamma / 2} \quad \text { at } \quad x=x_{\mathrm{b}} \text {. }
$$

The index 0 represents reference values at time $t_{\mathrm{B}}$. Since the Gurney model mentioned earlier implies that the particle velocity at the surface of the flyer exactly conforms with the flyer velocity, the same assumption is made here as well (see Fig. 7). 


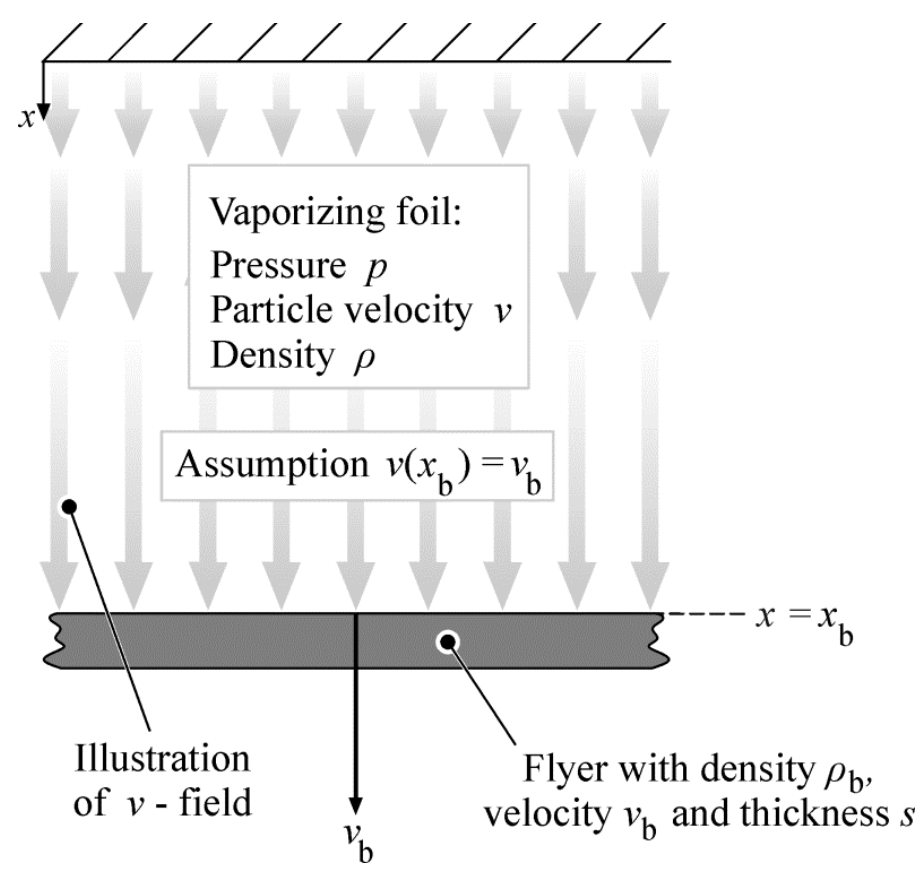

Figure 7: Schematic of one-dimensional flyer acceleration through VFA.

Equating Eq. (5) and Eq. (17) then results in a non-linear differential equation for the flyer velocity:

$\frac{\mathrm{d} v}{\mathrm{~d} t}=K_{1} v^{-\gamma / 2} \quad$ at $\quad x=x_{\mathrm{b}}$

with

$$
K_{1}=\frac{p_{0} v_{0}^{\gamma / 2}}{s \rho_{\mathrm{b}}} \text {. }
$$

A closed-form analytical solution of Eq. (18) can be found by using the method of separation of variables.

$$
v(t)=\left(\frac{2+\gamma}{2} \cdot\left(K_{1} t+K_{2}\right)\right)^{\frac{2}{2+\gamma}}
$$

The constants $K_{1}$ and $K_{2}$ are determined by the boundary value problem $v\left(t_{\mathrm{B}}\right)=v_{0}$ and $v\left(t_{\mathrm{E}}\right)=v_{\max }$, which eventually provides the following:

$$
\begin{aligned}
& K_{1}=\frac{2 v_{\max }(2+\gamma) / 2-2 v_{0}^{(2+\gamma) / 2}}{(2+\gamma)\left(t_{\mathrm{E}}-t_{\mathrm{B}}\right)}, \\
& K_{2}=\frac{2 v_{0}^{(2+\gamma) / 2}}{2+\gamma}-K_{1} t_{\mathrm{B}},
\end{aligned}
$$

and by association 
$p_{0}=p\left(t_{\mathrm{B}}\right)=\frac{K_{1} s \rho_{\mathrm{b}}}{v_{0}^{\gamma / 2}}$.

The pressure has its highest value at $t_{\mathrm{B}}$ because the volume of the foil is still confined right before the initiation of the burst. Afterwards, the pressure as well as the density of the expanding vapor decrease. By contrast, the velocity increases until the maximum velocity is reached, naturally followed by a deceleration stage which is not considered in the model presented here. For a given energy deposition and, thus, maximum velocity, the peak pressure increases for lower values of $\left(t_{\mathrm{E}}-t_{\mathrm{B}}\right)$, meaning for shorter durations of vapor expansion. On the other hand, at elevated energy depositions both the pressure and the velocity increase for a constant value of $\left(t_{\mathrm{E}}-t_{\mathrm{B}}\right)$. Since chemical reactions of the vapor are neglected in the model, the influence of the foil material on the flyer velocity is mainly given by the simplified Gurney model in Eq (10). Attention should be paid to the fact that the model is capable of providing the pressure-time, velocity-time, and displacementtime history of the flyer just between the two points in time $t_{\mathrm{B}}$ and $t_{\mathrm{E}}$. Since the displacement $D(t)$ is calculated by integrating velocity over time, the model can only be applied if the impact between flyer and target $\left(v=v_{\mathrm{im}}\right)$ occurs at or before $D\left(t_{\mathrm{E}}\right)$. Potential errors between the model and experimental data may also be attributed to the fact that adiabatic heating and rate effects causing changes in the yield stress of the flyer material prior to the burst are not covered by the present model. If all other values are kept constant in the model, it can be shown that a decreased yield stress results in a slightly lower flyer velocity at a given distance, which is physically reasonable.

\section{Experimental procedure}

All experiments were performed using actuators connected to a Maxwell-Magneform pulse generator having eight parallel capacitors. Each capacitor is discharged by two parallel ignitron switches. The power supply has a total capacitance of $C=426 \mu \mathrm{F}$, an internal resistance of $R_{\mathrm{i}}=10 \mathrm{~m} \Omega$, an internal inductance of $L_{\mathrm{i}}=100 \mathrm{nH}$, and a maximum charging energy of $16 \mathrm{~kJ}$ at a charging voltage of $8.66 \mathrm{kV}$. The resultant short-circuit frequency is in the range of $25 \mathrm{kHz}$. The basic experimental setups of the VFAW and the MPW system are quite similar, as can be seen in Fig. 8. 


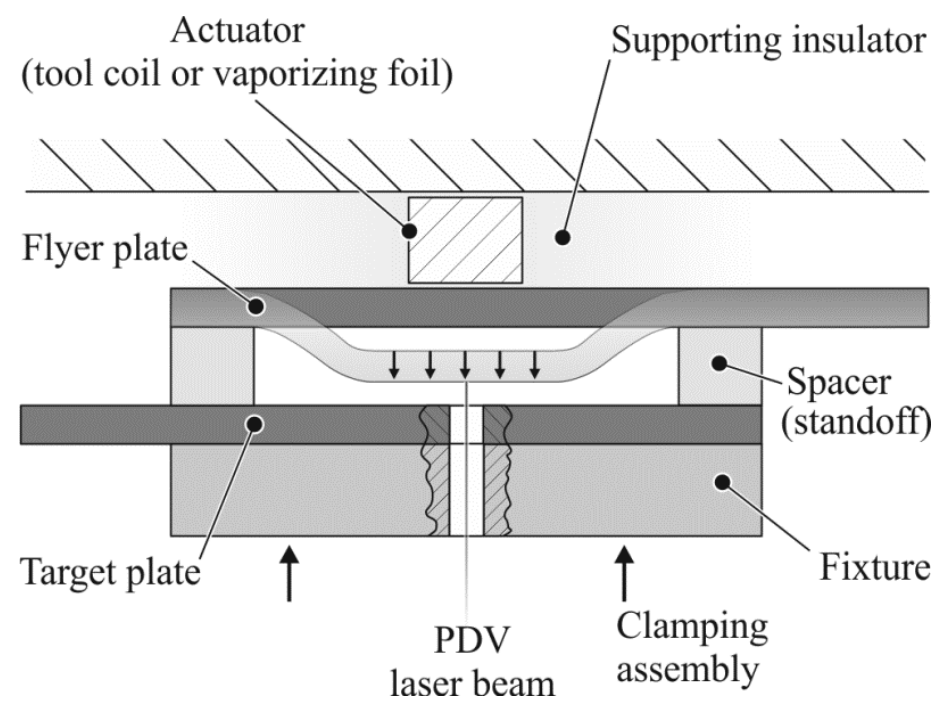

Figure 8: Schematic of the VFAW and MPW setup.

The actuator type, either a MPW coil or a vaporizing foil, is electrically insulated from and in close proximity to the sheet metal flyer. Spacers, whose height defines the standoff distance, allow space for the flyer to be accelerated plastically by the pressure pulse before hitting the target. The laser beam of the photonic Doppler velocimetry (PDV) system, which is addressed later in this section, is aligned orthogonally to the flyer surface through holes drilled in the target plate and fixture. This diagnostic tool is used to acquire velocity-time histories over the course of each experiment. The target hole is centered in relation to the upper surface of the actuator. For both the MPW and the VFAW experiments the parameters varied are standoff distance and charging energy of the capacitor bank, resulting in different impact angles and velocities. On that account, a full factorial matrix containing three different energies $(4.8 \mathrm{~kJ}, 6.4 \mathrm{~kJ}$ and $8 \mathrm{~kJ})$ and three different standoff distances $(1.1 \mathrm{~mm}, 2.1 \mathrm{~mm}$ and $3.4 \mathrm{~mm})$ - yielding nine combinations per process - was chosen. Partial repetitions were done to ensure statistical certainty. Test matrices summarizing the experiments are given in Table 1 a) and b). As the flyer velocity was recorded over time, experiments with higher standoff distances could be used to also evaluate velocities at distances that correspond to the lower standoff distances. 
Table 1: Test matrix for a) VFAW experiments, b) MPW experiments.

\begin{tabular}{|c|c|c|c|c|c|}
\hline \multirow{2}{*}{\multicolumn{2}{|c|}{$\begin{array}{l}\text { a) VFAW experiments } \\
X=1 \text { experiment }\end{array}$}} & \multicolumn{3}{|c|}{ Charging energy } & \multirow{3}{*}{$\begin{array}{l}\text { Flyer velocity } \\
\text { also evaluated } \\
\text { at distance: } \\
-\end{array}$} \\
\hline & & $4.8 \mathrm{~kJ}$ & $6.4 \mathrm{~kJ}$ & 8 kJ & \\
\hline \multirow{3}{*}{$\begin{array}{l}\text { Standoff } \\
\text { distance }\end{array}$} & $1.1 \mathrm{~mm}$ & X X & $X$ & X & \\
\hline & $2.1 \mathrm{~mm}$ & $X$ & $X$ & X X X & $1.1 \mathrm{~mm}$ \\
\hline & $3.4 \mathrm{~mm}$ & $\mathrm{X}$ & X X X & $\mathrm{X}$ & $1.1 \mathrm{~mm} ; 2.1 \mathrm{~mm}$ \\
\hline
\end{tabular}

\begin{tabular}{|l|c|c|c|c|l|}
\hline \multicolumn{2}{|l|}{ b) MPW experiments } & \multicolumn{3}{|c|}{ Charging energy } & $\begin{array}{l}\text { Flyer velocity } \\
\text { also evaluated } \\
\text { at distance: }\end{array}$ \\
\cline { 1 - 5 } X = 1 experiment & $\mathbf{4 . 8} \mathbf{~ k J}$ & $\mathbf{6 . 4} \mathbf{~ k J}$ & $\mathbf{8 ~ k J}$ & X \\
\hline \multirow{2}{*}{$\begin{array}{l}\text { Standoff } \\
\text { distance }\end{array}$} & $\mathbf{2 . 1} \mathbf{~ m m}$ & $X$ & $X$ & $X$ & $1.1 \mathrm{~mm}$ \\
\cline { 2 - 6 } & $\mathbf{3 . 4} \mathbf{~ m m}$ & $X$ & $X$ & $X X X$ & $1.1 \mathrm{~mm} ; 2.1 \mathrm{~mm}$ \\
\hline
\end{tabular}

The horizontal distance between the spacers was always $32 \mathrm{~mm}$. The flyer and target material selected for all experiments is EN AW 5005A (AlMg1), a medium-strength aluminum alloy, which is commonly applied in lightweight constructions. The aluminum sheets were not coated. In quasistatic tensile tests the sheet metal was measured to have a yield strength of $130 \mathrm{MPa}$, an ultimate tensile strength of $153 \mathrm{MPa}$, and Young's modulus was found to be $70 \mathrm{GPa}$. These values refer to the direction of rolling. All specimens (flyer and target plates in both VFAW and MPW) had a thickness of $1 \mathrm{~mm}$, a width of $75 \mathrm{~mm}$, and a length of $100 \mathrm{~mm}$. The density of all aluminum parts (specimens and foils) is taken to be $2.70 \mathrm{~g} / \mathrm{cm}^{3}$. Furthermore, tensile tests of the welded sheets were performed to evaluate the weld quality. For reasons of safety to personnel, the setup for vaporizing foil actuators is always deployed in a shrapnel containment enclosure which also provides noise abatement and exhaust ventilation. The experimental assembly is shown in Fig. 9 where the setup is displayed inversely to previous VFAW figures. 


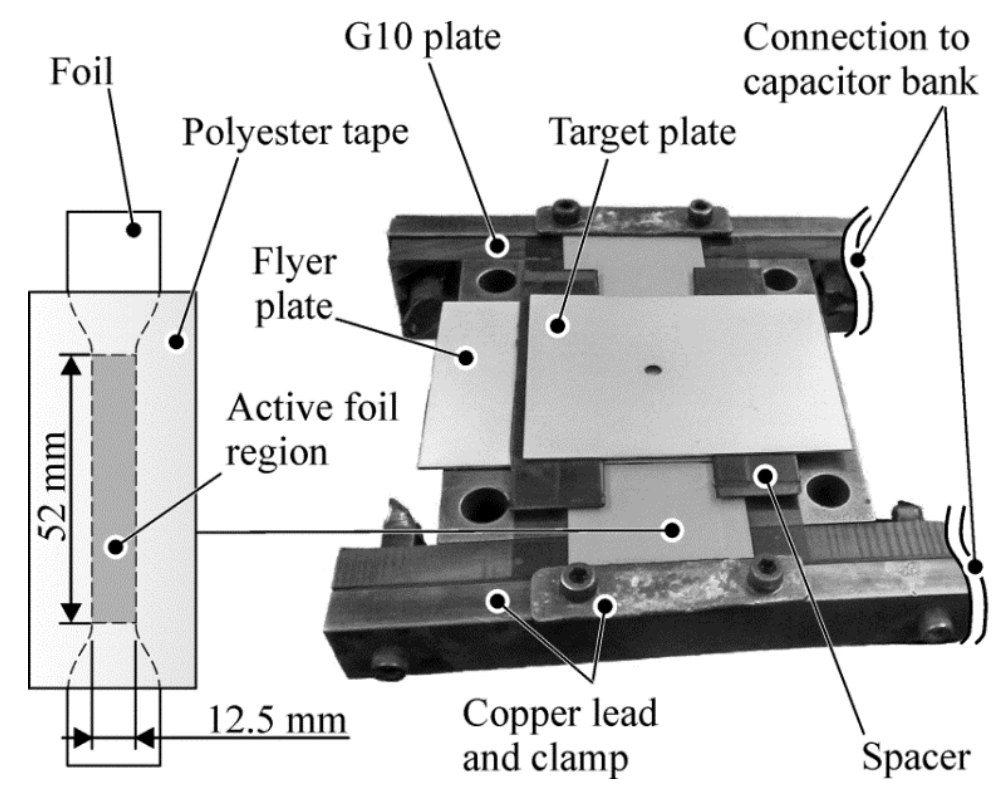

Figure 9: VFAW setup (upper fixture is not shown).

The foil is enclosed by polyester tape and additional Kapton tape (polyimide film) to guarantee good insulation against the flyer and the lower steel fixture. In turn, two G10 (glass-fiber reinforced epoxy) plates ensure the insulation of the steel fixture against the copper leads connected to the capacitor bank. The foil ends are not taped so there is good electrical continuity when clamped to the copper leads. Essentially uncoated pure aluminum foil (1000 series) with a thickness of $0.0762 \mathrm{~mm}$ was used as actuator material. Each foil was cut out using a robust steel template. The active foil region (see Fig. 9) is $52 \mathrm{~mm}$ long and $12.5 \mathrm{~mm}$ wide for every VFAW experiment. The bottom side of the flyer is also taped with Kapton, with the objective to avoid arc formation on the flyer surface and to ensure additional thermal and electrical insulation. Eventually, the setup is bolted together using four threaded rods. The principal element of the MPW assembly, also displayed inversely to the previous MPW figures, is pictured in Fig. 10. 


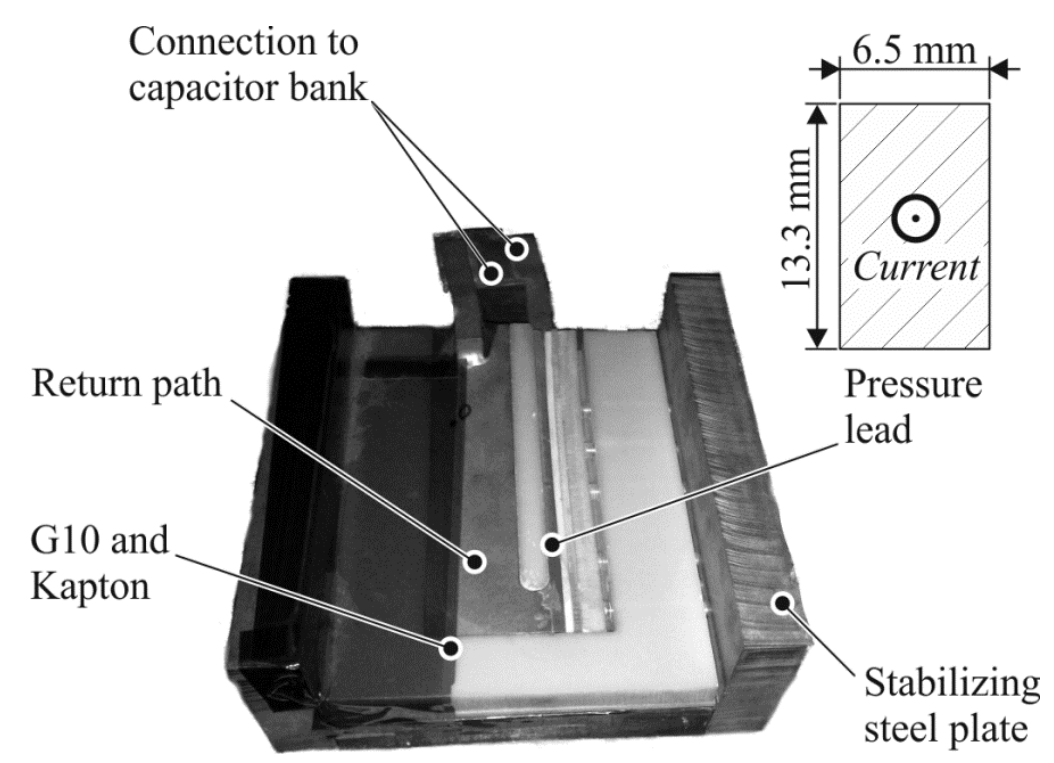

Figure 10: MPW coil (upper fixture, target, and flyer plates as well as spacers are not shown).

It features a one-turn coil made of copper embedded in an insulating G10 plate. The cross-section of the pressure lead has a width of $6.5 \mathrm{~mm}$ and a height of $13.3 \mathrm{~mm}$. All copper-to-copper connections of the coil are brazed and the only return path is positioned nearby and parallel to the pressure lead in order to keep the inductance of the coil low. The return path is several times wider than the pressure lead so as not to serve as a second pressure lead. Kapton tape is applied to the coil area for the purpose of electrical insulation between the coil and the flyer plate.

Measurement of the transient discharge current was accomplished using a $100 \mathrm{kA}$ : $1 \mathrm{~V}$ Rogowski coil around one output lead of the of the capacitor bank and voltage histories were measured by connecting a $1000: 1$ high-voltage probe to the terminals of the capacitor bank (in the connection area of the actuators). For the purpose of recording the data collected by these probes, both of them were connected to a LeCroy Waverunner 620Zi oscilloscope providing four channels, a bandwidth of $2 \mathrm{GHz}$, and a maximum sampling rate of $20 \mathrm{GS} / \mathrm{s}$. Further data processing and analysis was done by employing the commercial software Matlab. This extends to velocity-time histories acquired by the PDV system. This method of measuring high velocities is described in Strand et al. (2004). A laser beam with a wavelength of $\lambda_{0}=1550 \mathrm{~nm}$ is emitted by a focussing (or collimating) probe. It is then reflected from the surface of the moving flyer causing a Doppler-shifted light that re-enters the lens of the probe. Hence, the stationary probe serves as both source and receiver of the signal. A discrete short-time Fourier transform (STFT) of the detected signal allows creating a spectrogram plot of the beat frequency $f_{\mathrm{b}}(t)$ that is equal to the difference between the Doppler-shifted frequency and the frequency of the incident light signal. Flyer velocity histories $v(t)$ can then be computed as

$$
v(t)=\frac{\lambda_{0}}{2} f_{\mathrm{b}}(t)
$$


A time window of $500 \mu \mathrm{s}$, a sampling rate of $5 \mathrm{GS} / \mathrm{s}$, and a window size of 1000 with an overlap of 500 were chosen for the spectrograms of this study. Until the flyer impact, around 20 velocity points were picked from each spectrogram plot to generate $v(t)$ graphs. This method is similar to the one shown in Vivek et al. (2014c). All key components of the PDV system used for the experiments conform to those presented in Daehn et al. (2008).

\section{Analysis of experiments}

\subsection{Energy deposition}

As mentioned above, the amount of energy deposited into the foil prior to the instant when the foil bursts ( $E_{\mathrm{D}}$ according to Eq. (1)) denotes an important value in the context of VFAW. Corresponding experimental results are collected in Fig. 11, regardless of the standoff distance chosen for welding.

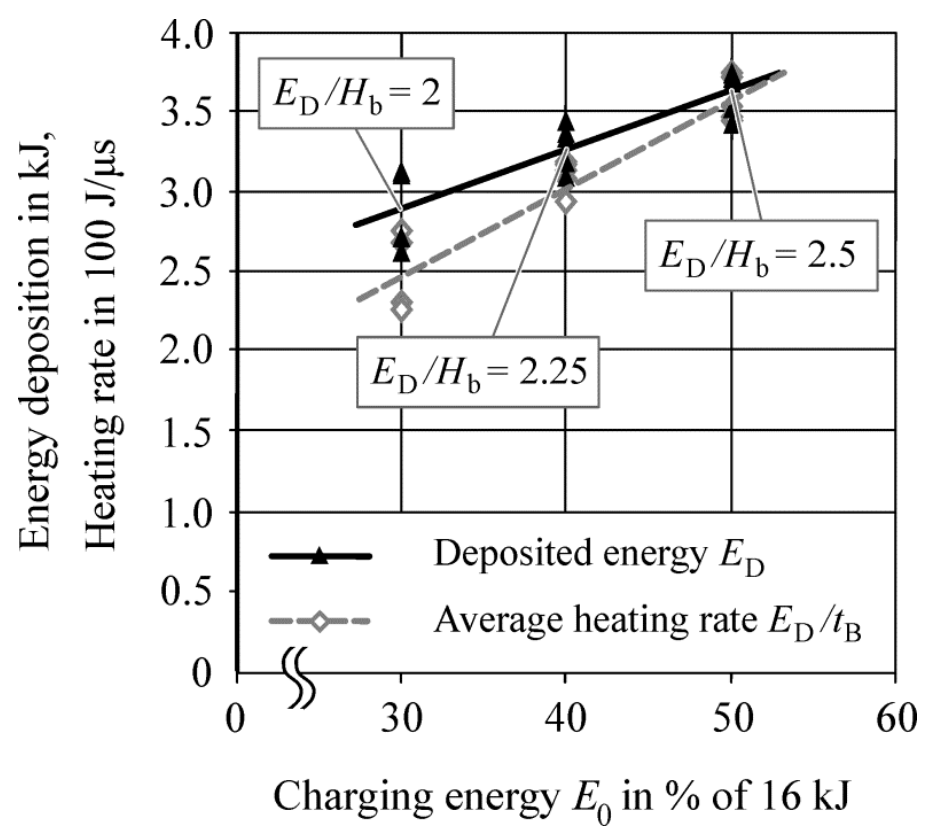

Figure 11: Influence of charging energy on energy deposition in VFAW experiments. The burst time was consistently around $11 \mu \mathrm{s}$.

Neglecting energy losses in the copper parts of the VFAW setup, a consideration of the ratio of average energy deposition to the latent heat of vaporization for the mass of the active foil region, $H_{\mathrm{b}}=c \cdot \Delta H(\Delta H=10.78 \mathrm{MJ} / \mathrm{kg}$ for aluminum following Davis (1993)), shows an increase from the value of 2 at a charging energy of $4.8 \mathrm{~kJ}$ to 2.5 at $8 \mathrm{~kJ}$. The burst currents range from $98 \mathrm{kA}$ at $4.8 \mathrm{~kJ}$ to $110 \mathrm{kA}$ at $6.4 \mathrm{~kJ}$ to $123 \mathrm{kA}$ at $8 \mathrm{~kJ}$ of charging energy, while the associated peak voltages range from $5.4 \mathrm{kV}$ to $6.5 \mathrm{kV}$ to $7.5 \mathrm{kV}$. These observations emphasize the assertion that the amount of energy that can be deposited until $t_{\mathrm{B}}$ is evidently not a constant for a given metal, as discussed in Section 2.2. The accompanying increase in average heating rates $E_{\mathrm{D}} / t_{\mathrm{B}}$ mapped in Fig. 11 also supports the idea of a rate dependency. The burst times observed are about the same for all 
experiments (average of $10.78 \mu \mathrm{s}$ ), so more energy is supplied to the foil during a time step when the initial charging energy of the capacitor is raised. That is to say, the energy deposited increases with charging energy if the circuit elements of the pulse generator $\left(R_{\mathrm{i}}, L_{\mathrm{i}}, C\right)$ are not changed over the course of experiments. It is, however, conspicuous that there are relatively large ranges (in the area of $15 \%$ ) concerning $E_{\mathrm{D}}$ for a given charging energy and, thus, there are some overlaps with the next value of input energy (compare Fig. 11). One reason for this could be the stochastic nature of electrical vaporizations as they are based on the occurrence of instabilities. The observed increases only show a relatively weak linear correlation on average, meaning that almost doubling the charging energy just leads to a $25 \%$ higher ratio of $E_{\mathrm{D}} / H_{\mathrm{b}}$.

Regarding electromagnetic forming, the relevant energy partially converted into kinetic and deformation energy of the flyer is not ohmic heating, but magnetic energy produced by the actuator. It is therefore useful to look at the coil currents in this context. The peak currents obtained linearly increase with the charging energy from $225 \mathrm{kA}$ to $270 \mathrm{kA}$ to $307 \mathrm{kA}$, which is more than twice as high as the highest value of the VFAW experiments. The corresponding peak voltages in MPW conform to the initial charging voltages $(4.7 \mathrm{kV}$ at $4.8 \mathrm{~kJ}, 5.5 \mathrm{kV}$ at $6.4 \mathrm{~kJ}, 6.1 \mathrm{kV}$ at $8 \mathrm{~kJ})$ In general, the workpiece deformation involves non-linear workpiece and mutual inductances and thus a timevarying frequency behavior. Referring to Bühler and Bauer (1968), a significant frequency $f$ can be calculated on the basis of the point when the peak coil current is reached, $\Delta t_{\text {rise }}$.

$f=\frac{1}{4 \Delta t_{\text {rise }}}$

Again, the remaining circuit elements were not varied, resulting in a frequency of $f=19.7 \mathrm{kHz}$ for every energy level.

\subsection{Flyer velocities in VFAW and MPW}

All other things being equal, higher energy depositions in case of VFAW and higher peak currents in case of MPW lead to higher flyer plate velocities. The velocities recorded with the PDV system are treated in this paragraph. Fig. 12 compiles flyer plate velocities at certain distances $D$ and charging energies for both processes, VFAW and MPW. 


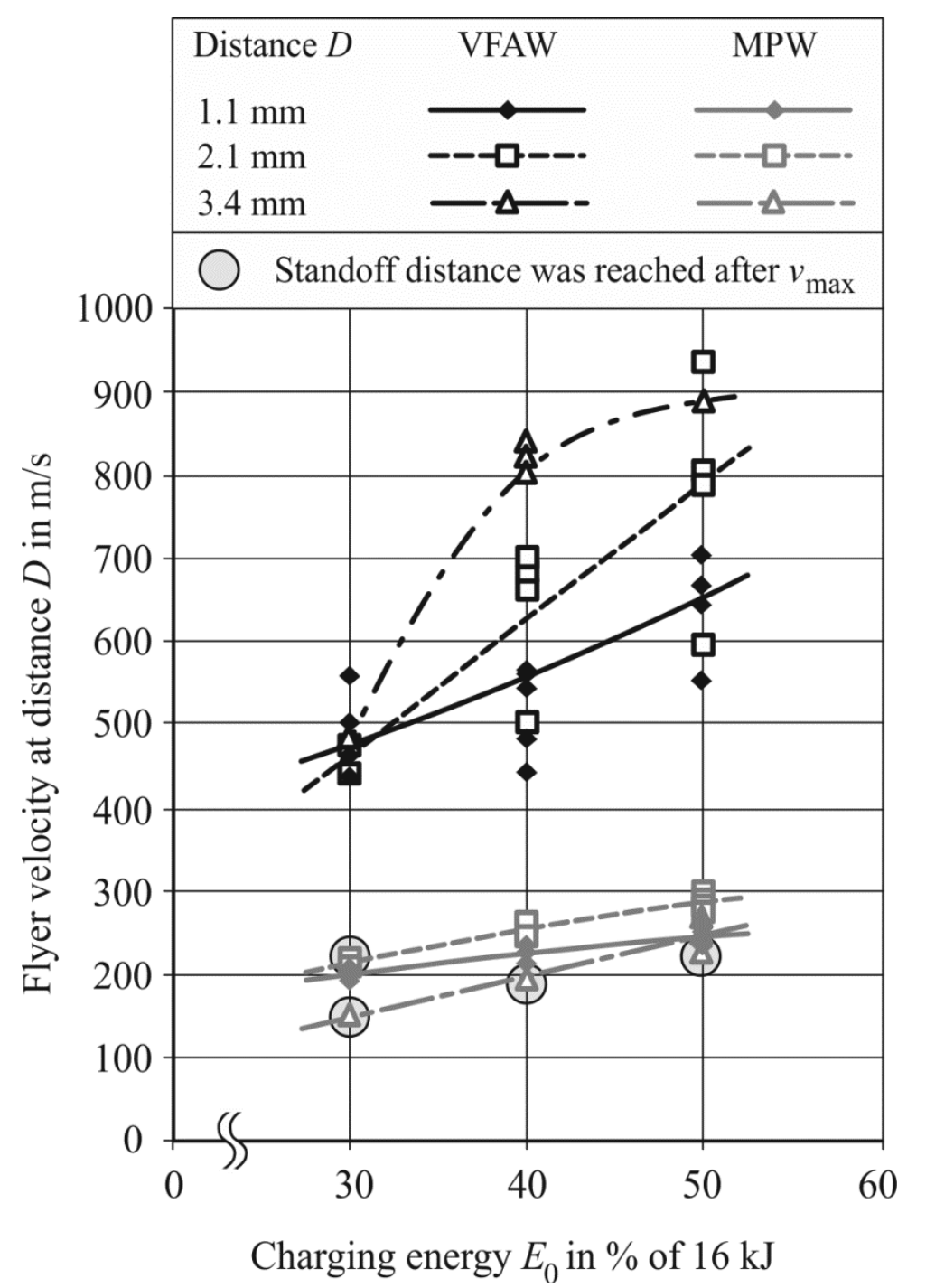

Figure 12: Comparison of flyer velocities in VFAW and MPW at certain distances and energy levels using PDV.

The most notable fact is that vaporizing foils provide flyer velocities up to three times higher as compared to MPW at the same charging energy, in numbers $930 \mathrm{~m} / \mathrm{s}$ versus $300 \mathrm{~m} / \mathrm{s}$ at the maximum. Similar to the energy deposition, for an identical experimental configuration the VFAW velocities shown in Fig. 12 exhibit deviations of up to $25 \%$ with regard to the corresponding average value. Resulting overlaps of velocity between different charging energies make it difficult to give precise statements about correlations. Besides the mentioned stochastic nature of instabilities during the energy deposition, the partly significant scatter for identical experimental configurations may be attributed to edge effects of the foil. This means that imperfections or sharp edges of the foil due to the cutting during the manufacture of the foil samples can cause local energy concentrations in undesired regions during the vaporization, which eventually results in lower flyer velocities. This assertion is supported by the work of Richardson et al. (1988) who underline that the foil corners should be rounded carefully to avoid such a non-uniform heating. On average, however, the 
following statements can be drawn for the trend lines displayed in Fig. 12. The flyer velocities at distances of $1.1 \mathrm{~mm}$ do not increase as strongly with energy input as the velocities at larger standoff distances. An explanation for this is given by the idea that the available energy is not yet converted into kinetic energy of the flyer at such short distances, meaning that more travel is required if substantially higher impact velocities are expected to be generated without changing the input energy. The trend line for the standoff distance of the $3.4 \mathrm{~mm}$ increases, in turn, stronger from $4.8 \mathrm{~kJ}$ to $6.4 \mathrm{~kJ}$ than from $6.4 \mathrm{~kJ}$ to $8 \mathrm{~kJ}$. As long as the maximum possible velocity is not yet reached at the impact, a higher standoff distance would be needed to make even higher flyer velocities possible at $8 \mathrm{~kJ}$. Hence, the VFAW velocity trend line for $3.4 \mathrm{~mm}$ rather increases in a non-linear manner with charging energy, whereas almost linear correlations can be obtained for lower distances. Velocities recorded during the MPW experiments do not show a variance like those of VFAW. None of the MPW experiments yielded an actual weld (joining partners were removable by hand), while all VFAW specimens were solidly welded. It must, however, be noted that neither of the setups was optimized in a specific manner. In case of MPW, peak currents in the order of $300 \mathrm{kA}$ at a charging energy of $8 \mathrm{~kJ}$ are already in the maximum admissible regime of the pulse generator. That is why no higher energy was tried to achieve higher velocities, and, thus actual magnetic pulse welds. It is important to note that the impact velocity is not necessarily equal to the maximum velocity. The peak value can also occur before hitting the target (see MPW experiments in Fig. 12) or the flyer may still be accelerating at the point of impact. This can also be seen in Fig. 13, where selected velocity-time curves of the VFAW and MPW experiments are plotted for the same initial configuration.

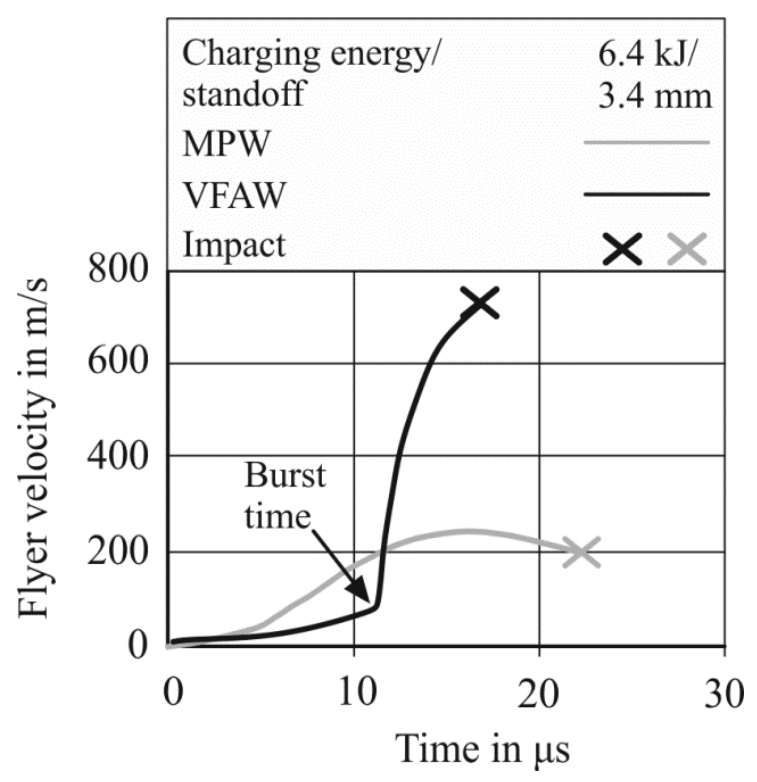

Figure 13: Selected velocity-time curves generated from PDV data for MPW and VFAW.

Further, the influence of the Lorentz force on the flyer velocity when employing VFA may be derived from Fig. 13: Prior to the burst, the foil acts as a tool coil in EMF. In this particular case, the 
electromagnetic launch provides velocities of about $50 \mathrm{~m} / \mathrm{s}$, followed by a rapid increase at the instant of vaporization. As opposed to this, the velocity curve describing the MPW experiment proceeds more continuously.

\subsection{Testing of welded joints}

One method of evaluating the quality of a welded lap joint is to compare its tensile shear strength with an appropriate parameter of the parent material. To express strength in terms of stress, the actual joining area as well as the stress distribution over this area must be known, which is usually hard to measure non-destructively and is unknown in the present case. Besides, bending moments in the lap joint affect the force measurements during a tensile test. Since the point when necking begins - the ultimate tensile strength - is characterized by the maximum force, it is reasonable to compare the maximum tensile force a lap joint can bear, $F_{\max }$, with the one of a reference strip having the same cross-sectional geometry as the weakest joining partner, $F_{\text {UTS }}$ (strength ratio $F_{\text {max }} / F_{\text {UTS }}$ ). This procedure could only be performed for the VFAW specimens because no magnetic pulse welds were achieved. Resultant strength ratios are depicted in Fig. 14 a.

a)

D

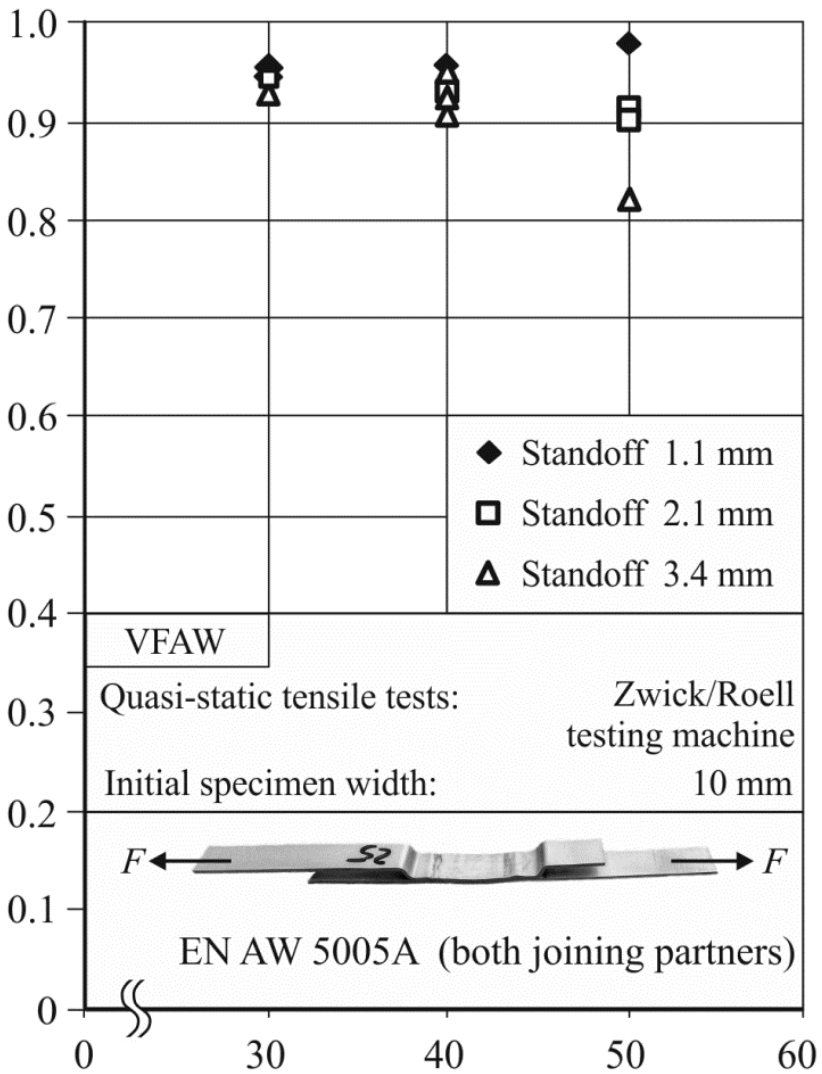

Charging energy $E_{0}$ in $\%$ of $16 \mathrm{~kJ}$ b)

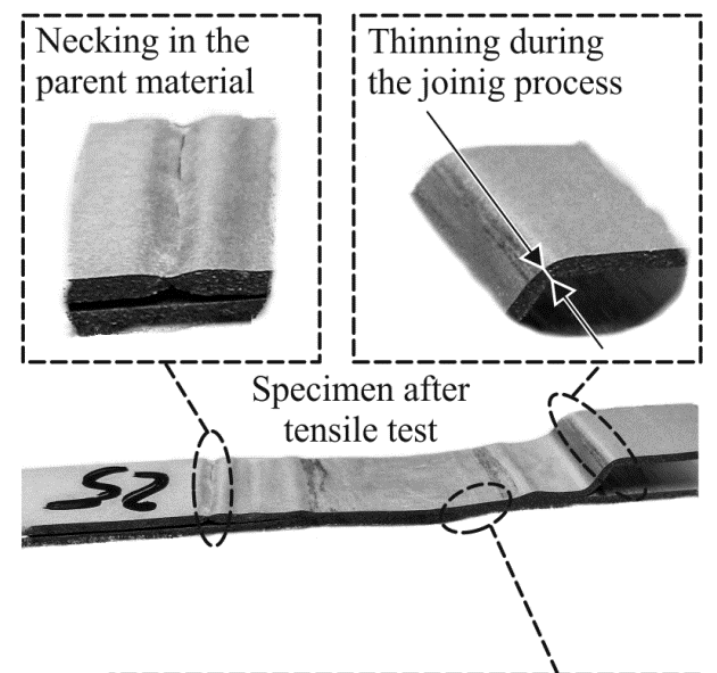

c) [Microsection (for $\overline{8} \mathrm{~kJ}$ charging energy)

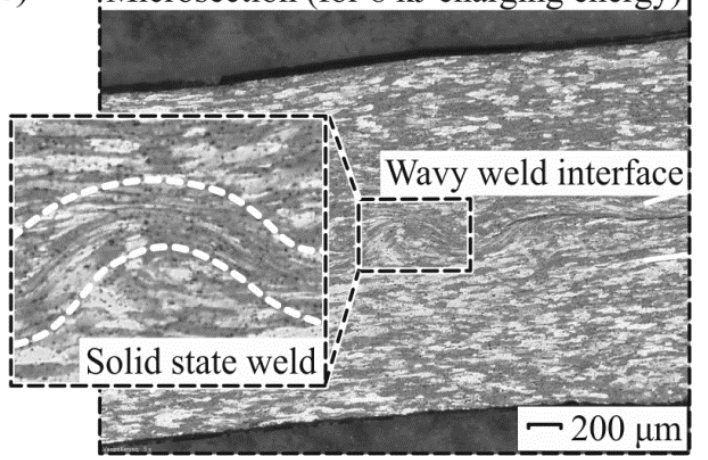

Figure 14: Evaluation of weld quality for VFAW experiments. a) Tensile test results for different charging energies and standoff distances. b) Necking and thinning in the specimen. c) Etched microsection of an exemplary weld seam. 
Here, it can be seen that the strength ratio is close to one almost independent of energy input and standoff distance. Even though the actual impact angle is unknown in this case, larger standoff distances imply larger impact angles. Further, as shown before, greater charging energies enable greater impact velocities. All investigated energies and standoff distances are apparently in a range where the maximum strength of the weld is reached anyway, which indicates a large process window for the given material combination. Necking always occurred in one of the joining partners farther away from the clamping instead of in the weld zone. It can therefore be stated that the shear strength of the VFAW joints is at least as high as the ultimate strength of the parent material. Owing to the clamping force the flyer plate is subjected to in the region where the spacers are positioned (clamp area), stress ratios lower than one can be explained through thinning effects during the forming stage at that very place, resulting in a reduced maximum bearable test load. This statement is supported by the fact that necking always started in the clamp area, which is pictured in Fig. 14 b. Due to elevated forming pressures it is evident that higher charging energies facilitate thinning effects at larger standoff distances (compare Fig. 14 a). The very first impact onto the target does not occur under an oblique angle. Thus, a rebound effect is observable at the center, so that actual (symmetric) weld seams are restricted to a small region near the center. Fig. $14 \mathbf{c}$ shows a micrograph of the interface cross-section of a weld zone for an $8 \mathrm{~kJ}$ experiment which indicates the typical wavy pattern including regions where neither interlayers nor melt pockets could be found. Consequently, a solid state weld can be expected there.

\section{Verification of the analytical model for VFA}

In this paragraph, the simplified analytical model presented within the scope of this work (Eq. (20)(23)) is applied to the current and voltage traces measured during the VFAW experiments (compare Fig. 6). The results are compared with the corresponding results generated from PDV data for the purpose of evaluating the accuracy and, therefore, the general applicability of the model. Since the impact with the target happens at a predefined distance (standoff distance), the values at those particular distances are of most interest when computing the flyer velocity and its time integral, the

displacement. To obtain a comprehensive overview concerning all vaporizing foil experiments, the analytically calculated and recorded velocities are compiled in Fig. 15 for the varied charging energies and distance levels. 

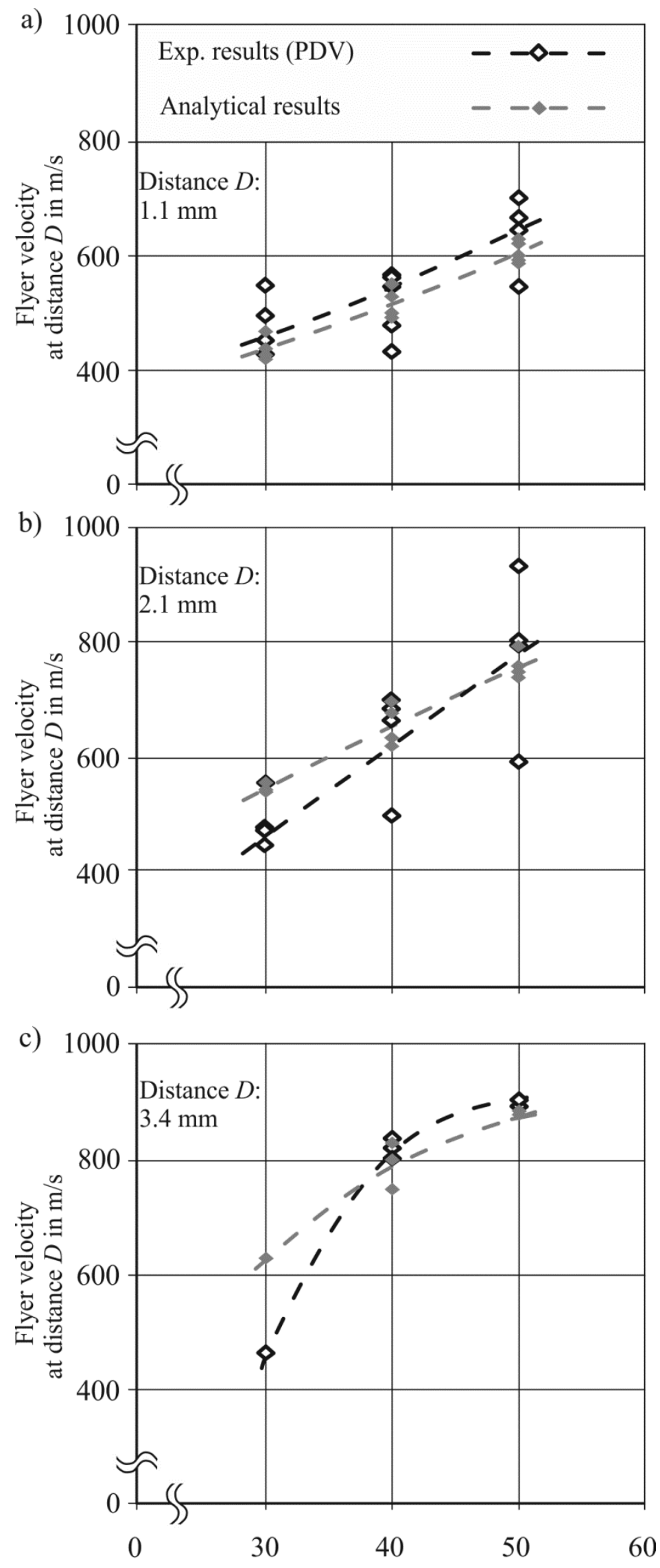

Charging energy $E_{0}$ in $\%$ of $16 \mathrm{~kJ}$

Figure 15: Measured and analytical flyer plate velocities in VFAW for different charging energies and distances of a) $1.1 \mathrm{~mm}$, b) $2.1 \mathrm{~mm}$, and c) $3.4 \mathrm{~mm}$. 
Naturally, the basic courses of the trend lines equal those of Fig. 12 as both figures are based on the same experiments. Since the model involves energy depositions $E_{\mathrm{D}}$, their variances also affect the analytical results. Like for the experimentally obtained flyer velocities, consequent overlaps of calculated velocities between different charging energies complicate the establishment of clearly defined relationships for any standoff distance in Fig. 15 a, b, and c. Nevertheless, the model properly reflects the influence of energy deposition on the velocity at distinct distances. Single deviations between experimental results and analytics range from perfect agreement to $34 \%$. The overall average deviation is about $11 \%$, which is an acceptable value if the model is used as a first approximation for the process design of a specific VFAW lap joint. The main reason for the deviations may be that the analytical model postulates a constant mass of vaporized aluminum (narrow active foil region) in Eq. (10), independent of energy input. The real energy density distribution is most likely not restricted to exactly the same foil region at varied energy depositions, though. Beside the velocities, the pressure acting on the flyer plate according to Eq. (5), which complies with Newton's second law, is also of interest. Amplitudes or peak values of pressure shall be compared with the analytical model, too. On the basis of smoothed experimental velocity curves, pressure-time histories can be approximated by applying a finite-difference method to Newton's second law. Central differences were used here for the necessary first time derivative of velocity. Peak pressures arising from this approach are collected in Fig. 16 and range from about $1 \mathrm{GPa}$ at a charging energy of $4.8 \mathrm{~kJ}$ to more than $2.5 \mathrm{GPa}$ at $8 \mathrm{~kJ}$. The observable linear course in peak pressure versus energy is qualitatively in accordance with the work of Grigoriev and Pavlenko (2009). It may be noted that peak pressures are only of the order of $100 \mathrm{MPa}$ or less when applying the same approach to the MPW experiments. 


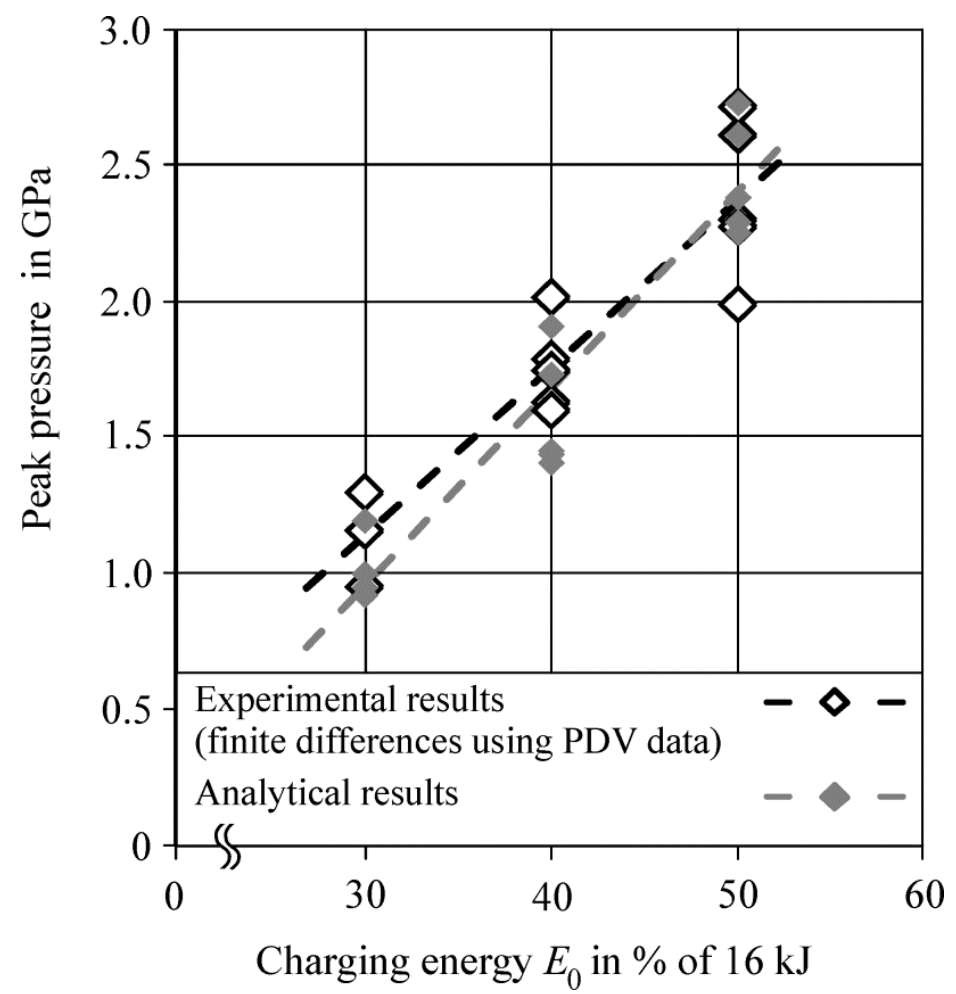

Figure 16: Analytical and (indirectly) measured peak pressures in VFAW for various charging energies regardless of standoff distance

With a maximum deviation of $18 \%$ and an average deviation of just $8 \%$ between analytical peak pressures and those indirectly obtained from PDV data, the model for VFA also provides an adequate pressure approximation. The peak or burst pressure is related to the instant of the burst when almost no flyer displacement has happened yet. Accordingly, the standoff distance chosen for welding does not really have an effect on the peak pressure. A complete and comparison of the temporal evolution of pressure and flyer velocity between model and experiment is given in Fig. 17, where a standoff distance of $3.4 \mathrm{~mm}$ is chosen in order to cover the largest possible displacement regarding the experiments conducted. 
a)

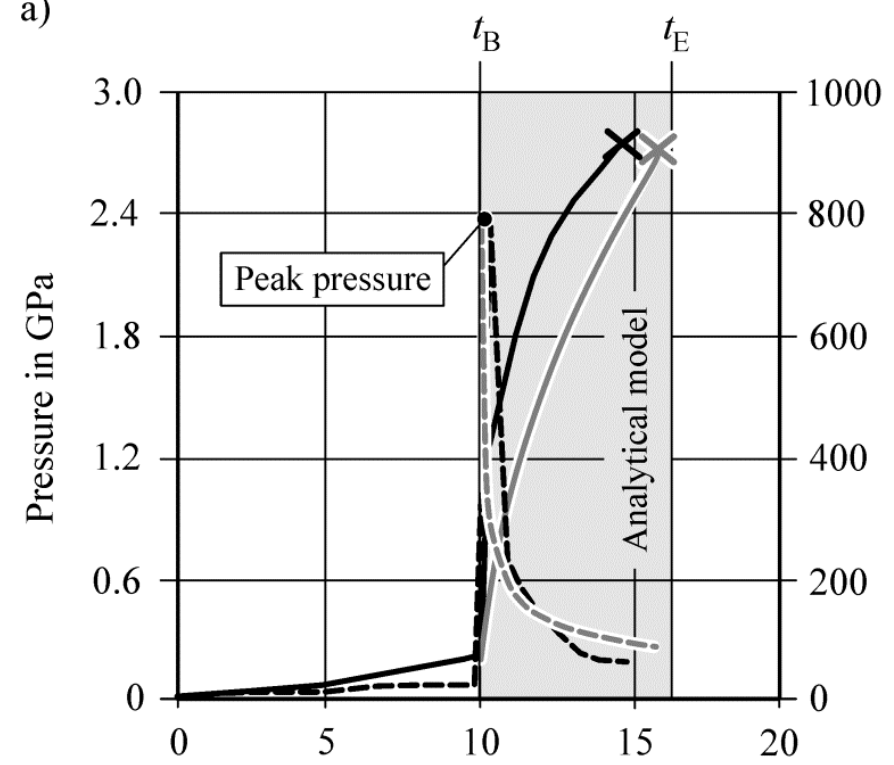

Time $t$ in $\mu \mathrm{s}$ b)

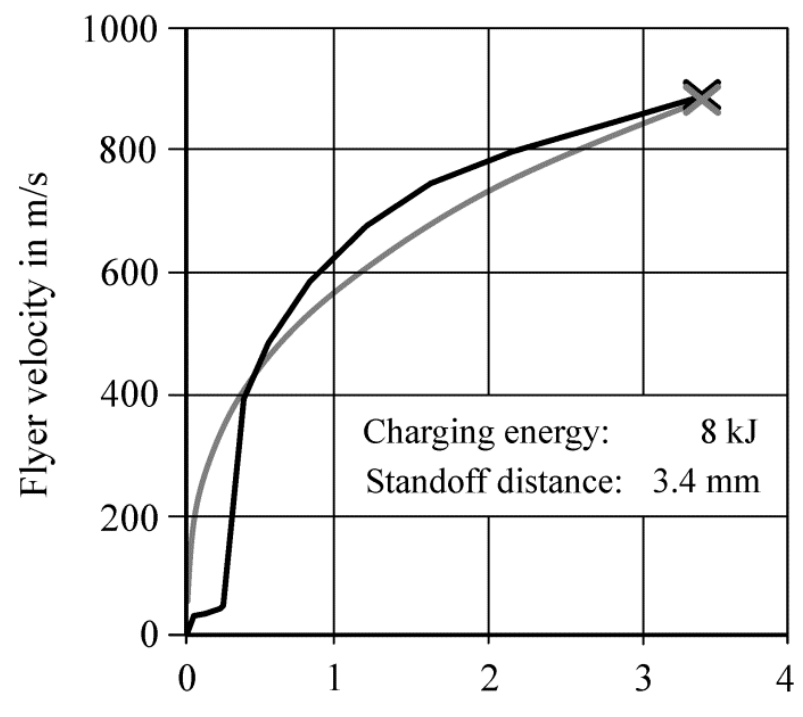

Displacement $D$ in $\mathrm{mm}$

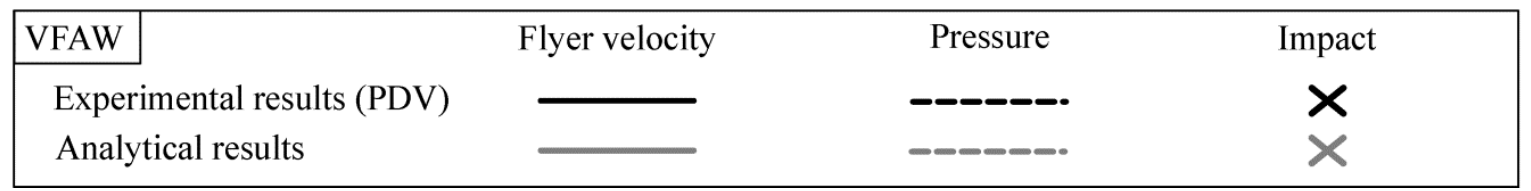

Figure 17: Comparison of analytical and experimentally obtained results for a charging energy of $8 \mathrm{~kJ}$ and a standoff distance of $3.4 \mathrm{~mm}$. a) Pressure and velocity plotted versus time. b) Velocity plotted versus displacement.

Fig. 17 a accentuates the domain of definition of the analytical model starting with burst time $t_{\mathrm{B}}$. According to PDV data, the impact on the target plate occurs at $t=14.9 \mu \mathrm{s}$, while $t=16.3 \mu \mathrm{s}$ is obtained for the analytically calculated impact, which is close to the end of the model area $\left(t_{\mathrm{E}}=16.7 \mu \mathrm{s}\right)$. Experimental and analytical curves show resembling shapes ending up at nearly the same impact velocity of about $880 \mathrm{~m} / \mathrm{s}$. The virtually instantaneous rise to a peak pressure of circa 2.4 $\mathrm{GPa}$ is outside the range of the model and is therefore not part of it. Even so, the peak pressure in itself and its subsequent decrease over time are sufficiently taken into account by the model. In Fig. 17 b, the velocity is plotted over the associated flyer displacement. Good agreement between analytics and experimental data in such a graph $(v(D))$ is of special importance for collision welding when deciding on the standoff distance of a joint. Since Fig. 17 represents one of the best comparisons, an example with a rather significant deviation between the experiment and the model of approximately $25 \%$ is given in Fig. 18 a and $\mathbf{b}$. 
a)

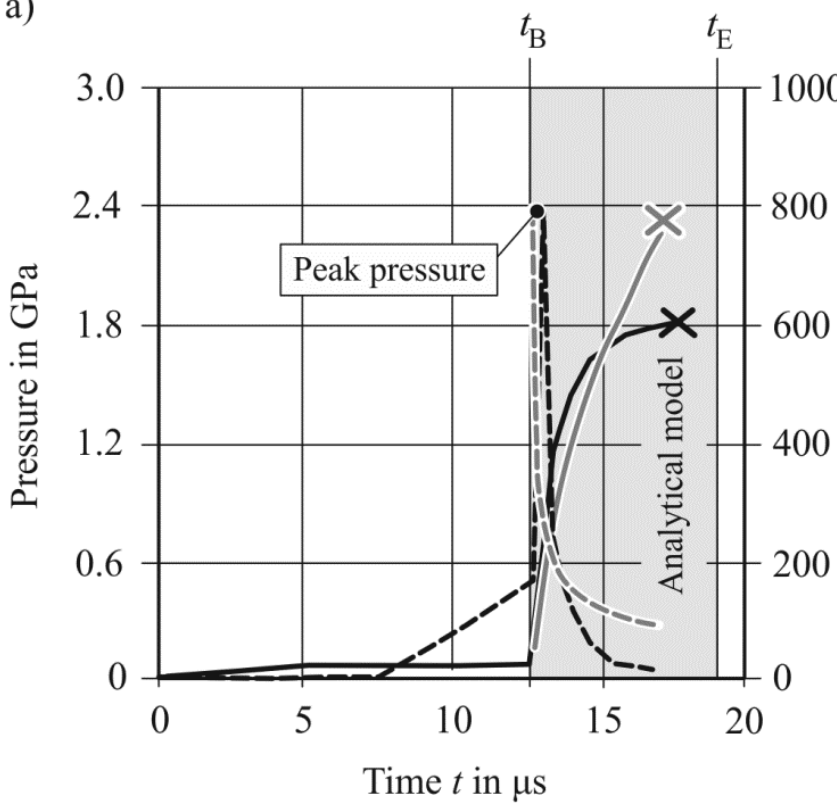

b)

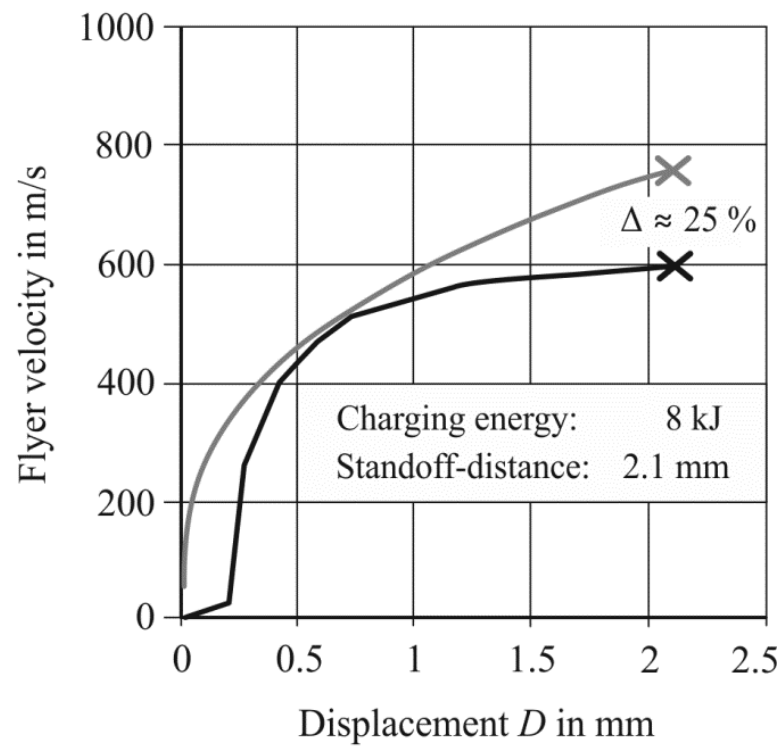

\begin{tabular}{|lccc|}
\hline VFAW & Flyer velocity & Pressure & Impact \\
\hline Experimental results (PDV) & - & --- & $\mathbf{X}$ \\
Analytical results & - & ---- & $\times$ \\
\hline
\end{tabular}

Figure 18: Comparison of analytical and experimentally obtained results for a charging energy of $8 \mathrm{~kJ}$ and a standoff distance of $2.1 \mathrm{~mm}$. a) Pressure and velocity plotted versus time. b) Velocity plotted versus displacement.

The analytically computed impact velocity in Fig. 18 follows a course similar to the one shown in Fig. 17 of up to $750 \mathrm{~m} / \mathrm{s}$ while the corresponding measured flyer velocity shows a significant decrease in acceleration so that only $600 \mathrm{~m} / \mathrm{s}$ were reached at impact, although the same charging energy of $8 \mathrm{~kJ}$ was chosen. This is the lower outlier also displayed in Fig. 15 b. Despite some distinct outliers the curves belonging to the VFAW experiments still feature the same qualitative progressions as in the previous example.

\section{Conclusions}

This work has shown that VFAW is a very suitable collision welding method and more efficient than MPW as applied to solid state lap welding. Employing the example of a lap joint of $1 \mathrm{~mm}$ thick EN AW 5005A sheets, both processes were directly compared under the same experimental conditions, in concrete terms: charging energies, configuration of the capacitor bank, specimen geometry, and standoff distances between flyer and target plate. Besides the advantage that vaporizing foils do not have tool life issues as they are disposable low cost actuators, flyer impact velocities up to $900 \mathrm{~m} / \mathrm{s}$ were recorded, which is three times higher than the maximum of the corresponding MPW experiments. Even at the lowest charging energy $(4.8 \mathrm{~kJ})$ impact velocities around $450 \mathrm{~m} / \mathrm{s}$ were reached using VFAW, with the result that a weld was formed in every VFAW experiment. By contrast, not even the highest energy input $(8 \mathrm{~kJ})$ yielded an impact velocity high enough to produce an actual magnetic pulse weld. Tensile tests showed that high joint strengths can be achieved with 
VFAW, meaning failure always happened in one of the joining partners while the weld seam was still intact. In addition, a simplified closed-form solution that allows plotting the time-dependent flyer plate velocity with respect to displacement has been introduced for VFA. With an average deviation of about $11 \%$ in terms of impact velocity, this analytical model is in satisfying agreement with PDV data, so that it can help predetermining the standoff distance needed for a specific VFAW joint. It would be desirable to further verify the model by investigating different flyer thicknesses and materials including those of lower electrical conductivity, since the irrelevancy of workpiece conductivity constitutes another advantage of vaporizing foils against MPW.

\section{Acknowledgements}

This paper is based on investigations of the Collaborative Research Center SFB/TR 10, subproject A10 "Joining by forming", which is kindly supported by the German Research Foundation (DFG). The authors would also like to acknowledge support of the U.S. Department of Energy through the Clean Energy Research Centre for Clean Vehicle Collaboration (CERC-CVC), award number DEPI0000012. Also appreciated is the financial support of the German Academic Exchange Service (DAAD-PROMOS grant). Many thanks to Steven Hansen from The Ohio State University for his support with the experiments and for the fruitful discussions.

\section{References}

Aizawa, T., 2003. Magnetic pressure seam welding method for aluminium sheets. Welding International 17 (12), 929-933, doi: 10.1533/wint.2003.3199.

Bealing, R., Carpenter, P.G., 1972. Exploding foil devices for shaping meg-amp current pulses. J. Phys. E: Sci. Instrum. 5, 889-892, doi: 10.1088/0022-3735/5/9/016.

Beerwald, C., 2005. Grundlagen der Prozessauslegung und -gestaltung bei der elektromagnetischen Umformung. Dr.-Ing. Dissertation, Universität Dortmund, ISBN 3-8322-4421-2.

Ben-Artzy, A. Stern, A., Frage, N., Shribman, V., Sadot, O., 2010. Wave formation mechanism in magnetic pulse welding. International Journal of Impact Engineering 37 (4), 397-404, doi: 10.1016/j.ijimpeng.2009.07.008.

Bühler, H., Bauer, D., 1968. Ein Beitrag zur Magnetumformung rohrförmiger Werkstücke. Werkstatt und Betrieb 110 (9), 513-516.

Chace, W.G., Levin, M.A., 1960. Classification of wire explosions. J. Appl. Phys. 31, 1298, doi: $10.1063 / 1.1735823$. 
Chau, H.H., Dittbenner, G., Hofer, W.W., Honodel, C.A., Steinberg, D.J., Stroud, J.R., Weingart, R.C., Lee, R.S., 1980. Electric gun: a versatile tool for high-pressure shock-wave research. Rev. Sci. Instrum. 51 (12), 1676-1681, doi: 10.1063/1.1136155.

Daehn, G.S., 2010. Energy field methods and electromagnetic sheet metal forming. In: Zhang, W. (Ed.), Intelligent Energy Field Manufacturing: Interdisciplinary Process Innovations. CRC Press, pp. 471504, ISBN 978-1420071016.

Daehn, G.S., Zhang, Y., Golowin, S., Banik, K., Vivek, A., Johnson, J.R., Taber, G., Fenton, G.K., Henchi, I., L'Eplattenier, P., 2008. Coupling experiment and simulation in electromagnetic forming using Photon Doppler Velocimetry. In: Proceedings of the 3rd International Conference on High Speed Forming ICHSF, Dortmund, Germany, pp. 35-44, online available at https://eldorado.tudortmund.de/handle/2003/27105.

Davis, J.R., 1993. Aluminum and Aluminum Alloys. ASM International, p. 643, ISBN 978-0871704962

Göbel, G., Kaspar, J., Herrmannsdörfer, T., Brenner, B., Beyer, E., 2010. Insights into intermetallic phases on pulse welded dissimilar metal joints. In: Proceedings of the 4th International Conference on High Speed Forming - ICHSF, Columbus OH, USA, pp. 127-136, online available at https://eldorado.tudortmund.de/handle/2003/27191.

Grigoriev, A.N., Pavlenko, A.V., 2009. Pressure generated by the electric explosion of metal foils. Technical Physics Letters 35 (9), 865-868, doi: 10.1134/S1063785009090235.

Harvey, G.W., Brower, D.F., 1958. Metal Forming Device and Method. US-Patent Nr. 2976907.

Henselek, A., Beerwald, M., Beerwald, C., 2004. Design and adaptation of EMF equipment - from direct acting multi-turn coils to separable tool coils for electromagnetic tube compression. In: Proceedings of the 1st International Conference on High Speed Forming - ICHSF, Dortmund, Germany, pp. 275-284, online available at https://eldorado.tu-dortmund.de/handle/2003/27029.

Jones, N., 1989. Structural impact, 1st ed.. Cambridge University Press, Cambridge, ISBN 978-0521628907.

Kamal, M., 2005. A uniform pressure electromagnetic actuator for forming flat sheets. Ph.D. Thesis, The Ohio State University, online available at http://rave.ohiolink.edu/etdc/view?acc_num=osu1127230699.

Kore, S.D., Imbert, J., Worswick, M.J., Zhou, Y., 2009. Electromagnetic impact welding of Mg to Al sheets. Science and Technology of Welding and Joining 14 (6), 549-553, doi: 10.1179/136217109X449201.

Lee, W.M., Ford, R.D., 1988. Pressure measurements correlated with electrical explosion of metals in water. Journal of Applied Physics 64 (8), 3851-3854, doi: 10.1063/1.341365.

Li, F., Mo, J., Li, J., Zhou, H., Huang, L., 2013. Study on the driver plate for electromagnetic forming of titanium alloy Ti-6Al-4V. Int. J. Adv. Manuf. Technol. 69 (1), 127-137, doi: 10.1007/s00170-0135002-1.

Loeb, L.B., 1927. Kinetic theory of gases, 1st ed.. McGraw-Hill Book Company, New York and London. 
Martins, J.B., Symonds, P.S., 1965. Mode approximations for impulsively loaded rigid plastic structures. Techn. Report from Brown University, Div. of Engineering, Providence RI, USA, online available at http://www.dtic.mil/docs/citations/AD0621580.

Mori, K., Bay, N., Fratini, L., Micari, F., Tekkaya, A.E., 2013. Joining by plastic deformation. CIRP Annals Manufacturing Technology 62 (2), 673-694, doi: 10.1016/j.cirp.2013.05.004.

Mousavi, S.A.A. Akbari, Sartangi, P.F., 2009. Experimental investigation of explosive welding of cptitanium/AISI 304 stainless steel. Materials and Design 30 (3), 459-468, doi: 10.1016/j.matdes.2008.06.016.

Nelson, L.S., Hogeland, S.R., Roth, T.C., 1999. Alumium-enhanced underwater electrical discharges for steam explosion triggering. Sandia Labs. Report, Albuquerque NM, USA, 58 pages, doi: $10.2172 / 12653$.

Osher, J.E., Barnes, G., Chau, H.H., Lee, R.S., Lee, C., Speer, R., Weingart, C., 1989. Operating characteristics and modeling of the LLNL 100-kV electric gun. IEEE Transactions on Plasma Science 17 (3), 392-402, doi: 10.1109/27.32247.

Pécseli, H.L., 2012. Waves and oscillations in plasmas, 1st ed.CRC Press, pp. 209-210, ISBN 9780415613033.

Psyk, V., Risch, D., Kinsey, B.L., Tekkaya, A.E., Kleiner, M., 2011. Electromagnetic forming - a review. J. Mater. Process. Tech. 211 (5), 787-829, doi: 10.1016/j.jmatprotec.2010.12.012.

Reissner, J., Müller-Duysing, M., Dannenmann, E., Ladwig, J., 1990. Biegen. In: Lange, K., UmformtechnikHandbuch für Industrie und Wissenschaft, Band 3: Blechbearbeitung, 2. Aufl.. Springer Verlag, pp. 243-310, ISBN 3-540-50039-1.

Richardson, D.D., Northeast, E.D., Ryan, P.F.X., 1988. An exploding foil flying plate generator. Materials Research Lab. Report, Melbourne, Australia, 37 pages.

Sarathi, R.,Chakravarthy, S.R., Venkataseshaiah, C., 2004. Studies on the generation and characterization of nanoalumina powder using wire explosion technique. International Journal of Nanoscience 3 (6), 819 - 827, doi: 10.1142/S0219581X04002711

Sarkisov, G.S., Struve, K.W., McDaniel, D.H., 2004. Effect of current rate on energy deposition into exploding metal wires in vacuum. Physics of Plasmas 11 (10), 4573-4581, doi: 10.1063/1.1784452.

Schmidt, S.C., Seitz, W.L., Wackerie, J., 1977. An empirical model to compute the velocity histories of flyers driven by electrically exploding foils. Los Alamos Scientific Laboratory Report, Albuquerque NM, USA, 14 pages.

Sedoi, V.S., Mesyats, G.A., Oreshkin, V.I., Valevich, V.V., Chemezova, L.I., 1999. The current density and the specific energy input in fast electrical explosion. IEEE Transactions on Plasma Science 27 (4), 845-850, doi: 10.1109/27.782248.

Shribman, V., 2008. Magnetic pulse welding for dissimilar and similar materials. In: Proceedings of the 3rd International Conference on High Speed Forming - ICHSF, Dortmund, Germany, pp. 13-22, online available at https://eldorado.tu-dortmund.de/handle/2003/27107. 
Sinton, R.P.W., 2011. Long distance exploding wires. Ph.D. Thesis, University of Canterbury, online available at http://hdl.handle.net/10092/6586.

Strand, O.T., Berzins, L.V., Goosman, D.R., Kuhlow, W.W., Sargis, P.D., Whitworth, T.L., 2004. Velocimetry using heterodyne techniques. In: Proc. SPIE 5580, 26th International Congress on High-Speed Photography and Photonics, Alexandria, VA, USA, doi: 10.1117/12.567579.

Tucker, T.J., Stanton, P.L., 1975. Electrical Gurney energy: a new concept in modeling of energy transfer from electrically exploded conductors. Sandia Labs. Report, Albuquerque NM, USA, 28 pages.

Verstraete, J., De Waele, W., Faes, K., 2011. Magnetic pulse welding: lessons to be learned from explosive welding. Sustainable Construction \& Design 2 (3), 458-464, ISSN 2032-7471.

Vivek, A., Brune, R.C., Hansen, S.R., Daehn, G.S., 2014a. Vaporizing foil actuator used for impulse forming and embossing of titanium and aluminum alloys. J. Mater. Process. Tech. 214 (5), 865-875, doi: 10.1016/j.jmatprotec.2013.12.003.

Vivek, A., Hansen, S.R., Daehn, G.S., 2014b. High strain rate metalworking with vaporizing foil actuator: Control of flyer velocity by varying input energy and foil thickness. Review of Scientific Instruments 85 (7), 075101, doi: 10.1063/1.4884647.

Vivek, A., Hansen, S.R., Liu, B.C., Daehn, G.S., 2013. Vaporizing foil actuator: a tool for collision welding. J. Mater. Process. Tech. 213 (12), 2304-2311, doi: 10.1016/j.jmatprotec.2013.07.006.

Vivek, A., Liu, B.C., Hansen, S.R., Daehn, G.S., 2014c. Accessing collision welding process window for titanium/copperwelds with vaporizing foil actuators and grooved targets. J. Mater. Process. Tech. 214 (8), 1583-1589, doi: 10.1016/j.jmatprotec.2014.03.007.

Wang, G., Zhao, J., Luo, B., Jiang, J., 2011. Magnetohydrodynamics of metallic foil electrical explosion and magnetically driven quasi-isentropic compression. In: Schulz, H. (Ed.), Hydrodynamics - Advanced Topics. InTech, pp. 347-378, ISBN 978-953-307-596-9.

Weddeling, C., Hahn, M., Daehn, G.S., Tekkaya, A.E., 2014. Uniform pressure electromagnetic actuator - an innovative tool for magnetic pulse welding. In: Proceedings of the International Conference on Manufacture of Lightweight Components - ManuLight 2014, Dortmund, Germany, Procedia CIRP, vol. 18, pp. 156-161, doi: 10.1016/j.procir.2014.06.124.

Weingart, R.C., Lee, R.S., Jackson, R.K., Parker, N.L., 1976. Acceleration of thin flyers by exploding foils: application to initiation studies. In: Proceedings of the 6th International Symposium on Detonation, Coronado CA, USA, pp. 653-663.

Winkler, R., 1973. Hochgeschwindigkeitsbearbeitung: Grundlagen und technische Anwendung elektrisch erzeugter Schockwellen und Impulsmagnetfelder, 1. Auflage. VEB Verlag Technik, Berlin.

Young, W.C., Budynas, R.G., 2002. Roark's formulas for stress and strain, 7th ed..McGraw-Hill, p. 193, ISBN 0-07-072542-X. 
Zhang, Y., 2010. Investigation of magnetic pulse welding on lap joint of similar and dissimilar materials. Ph.D. Thesis, The Ohio State University, online available at http://rave.ohiolink.edu/etdc/view?acc_num=osu1268135049.

Zhang, Y., Babu, S., Daehn, G.S., 2010. Impact welding in a variety of geometric configurations. In: Proceedings of the 4th International Conference on High Speed Forming - ICHSF, Columbus OH, USA, pp. 97-107, online available at https://eldorado.tu-dortmund.de/handle/2003/27194.

Zou, X.B., Mao, Z.G., Wang, X.X., Jiang, W.H., 2012a. Two different modes of wire explosion for nanopowder production. A Letters Journal Exploring the Frontiers of Physics 97 (3), 35004, doi: 10.1209/0295-5075/97/35004.

Zou, Y., He, B., Jiang, X., Wang, L., 2012b. Relationships between bridge foil parameters and input pulse current. In: Proceedings of the 2012 International Symposium on Safety Science and Technology, Procedia Engineering, vol. 45, 1020-1024, doi: 10.1016/j.proeng.2012.08.276 